\title{
1 Seasonality in Arctic Warming Driven By Sea Ice Effective Heat Capacity
}


Arctic surface warming under greenhouse gas forcing peaks in early winter and reaches its minimum during summer in both observations and model projections. Many

11 mechanisms have been proposed to explain this seasonal asymmetry, but disentangling these

12 processes remains a challenge in the interpretation of general circulation model (GCM)

13 experiments. To isolate these mechanisms, we use an idealized single-column sea ice model

14 (SCM) which captures the seasonal pattern of Arctic warming. SCM experiments demonstrate that as sea ice melts and exposes open ocean, the accompanying increase in effective surface heat capacity can alone produce the observed pattern of peak early winter warming by slowing the seasonal heating and cooling rate, thus delaying the phase and reducing the amplitude of the seasonal cycle of surface temperature. To investigate warming seasonality in more complex models, we perform GCM experiments that individually isolate sea-ice albedo and thermodynamic effects under $\mathrm{CO}_{2}$ forcing. These also show a key role for the effective heat capacity of sea ice in promoting seasonal asymmetry through suppressing summer warming, in addition to precluding summer climatological inversions and a positive summer lapse-rate feedback. Peak winter warming in GCM experiments is further supported by a positive winter lapse-rate feedback that persists with only the albedo effects of sea-ice loss prescribed, due to cold initial surface temperatures and strong surface-trapped warming. While many factors support peak early winter warming as Arctic sea ice declines, these results highlight changes in effective surface heat capacity as a central mechanism contributing to this seasonality. 
Arctic warming occurs during early winter, but the reasons for this seasonal pattern of warming are not well understood. We use experiments in both simple and complex models with certain sea-ice processes turned on and off to disentangle potential drivers of the early winter peak in Arctic warming. When sea ice melts and open ocean is exposed, surface temperatures are slower to reach the warm-season maximum and slower to cool back down below freezing in early winter. We find that this process alone can produce the observed pattern of maximum Arctic warming in early winter, highlighting a fundamental mechanism

41 for the seasonal pattern of Arctic warming.

\section{Introduction}

In both observations and model simulations, recent Arctic surface warming has outpaced the global average by a factor of more than two (Screen and Simmonds, 2010a; Serreze et al., 2009). While sea-ice melt and the ice-albedo feedback peak during summer, the strongest Arctic warming is observed several months later during early winter (Screen and Simmonds, 2010b). This seasonal asymmetry is also found in model projections, from the earliest model generations to the newest iteration of climate models in the Coupled Model Intercomparison Project phase 6 (CMIP6) (Deser et al., 2010; Hahn et al., 2021; Holland and

50 Bitz, 2003; Manabe and Stouffer, 1980). Figure 1 illustrates the seasonal pattern of Arctic warming within the fully-coupled Community Earth System Model version 2 (CESM2) (Danabasoglu et al., 2020). While consistent with other CMIP6 models in producing winteramplified Arctic warming, this model's inclusion of a 1pctCO2-4xext experiment illustrates a

54 full range of annually ice-covered, seasonally ice-free, and annually ice-free conditions. In this experiment, a $1 \%$-per-year increase in atmospheric $\mathrm{CO}_{2}$ is applied up to a quadrupling of 
pre-industrial concentrations in year 140 , with constant $\mathrm{CO}_{2}$ forcing thereafter. The evolving seasonal cycle of near-surface air temperature (TAS) area-averaged over non-land surfaces from $70-90^{\circ} \mathrm{N}$ in this experiment (Figure 1a) and the change in TAS with respect to a preindustrial control (piControl) experiment with greenhouse gas concentrations from the year 1850 (Figure 1b) show several key features: (i) stronger warming during winter than summer; (ii) peak warming in early winter for the first 150 years of the experiment; and (iii) a shift to peak warming in late winter for higher global warming levels later in the experiment, once early winter temperatures exceed the freezing point. While these features suggest that sea-ice loss plays a key role in setting the seasonal pattern of near-surface Arctic warming, they raise the question of how this pattern is produced.

Commonly proposed mechanisms linking sea-ice loss to seasonal asymmetry in Arctic warming include: (i) the delayed warming effect, in which increased surface solar absorption due to reduced summer ice cover contributes to seasonal ocean heat storage and its release to the atmosphere in winter; and (ii) the ice insulation effect, in which reduced sea-ice thickness and extent allows for stronger heat transfer from the relatively warm upper ocean to the colder atmosphere above particularly during winter, when the air-sea temperature difference is greatest (Deser et al., 2010; Manabe and Stouffer, 1980; Screen and Simmonds, 2010b). Seasonality in Arctic warming has also been attributed to longwave cloud and temperature feedbacks, including the lapse-rate and Planck feedbacks (Bintanja and van der Linden 2013; Lu and Cai, 2009; Pithan and Mauritsen, 2014; Sejas et al., 2014; Yoshimori et al., 2014). A positive winter lapse-rate feedback in the Arctic results from surface-trapped warming which produces weaker longwave emission to space than a vertically uniform atmospheric warming. As this surface-trapped warming is supported by a stable lower troposphere that inhibits vertical mixing, stronger stability in winter promotes a winter- 
peaking Arctic lapse-rate feedback (Cronin and Jansen, 2015; Hahn et al., 2020; Payne et al.,

2015). Seasonality in the Planck feedback would also contribute to greater warming in winter

than in summer due to a weaker increase in outgoing longwave radiation for a surface warming at initially colder temperatures (Pithan and Mauritsen, 2014).

Many of these mechanisms are interconnected, making it difficult to distinguish their relative importance for seasonality in Arctic warming. After seasonal ocean heat storage, the lapse-rate feedback is the second largest contributor to seasonal asymmetry in Arctic warming for models in the Coupled Model Intercomparison Project phase 5 and 6 (Hahn et al., 2021; Pithan and Mauritsen, 2014). Bintanja et al. (2011) and Hahn et al. (2020) suggest that the polar lapse-rate feedback depends on the base-state inversion strength, which itself depends on the existence of sea ice, poleward atmospheric heat transport, and atmospheric emissivity (Cronin and Jansen, 2015; Payne et al., 2015; Pithan et al., 2014). More recently, Boeke et al. (2021) find that while inversions are necessary for a positive lapse-rate feedback, this feedback depends more strongly on the amount of surface warming than on the degree of stable stratification. As a result, a more-positive lapse-rate feedback in winter could result from any process that promotes stronger bottom-heavy atmospheric warming, including the ice-albedo feedback (Feldl et al., 2017; Graversen et al., 2014). Dai et al. (2019) and Chung et al. (2021) further suggest that seasonal ocean heat storage and sea-ice insulation loss are necessary to kickstart the winter lapse-rate feedback via increased turbulent heat release to the atmosphere over newly opened ocean. Separating these potentially interdependent ice-

100 albedo, seasonal ocean heat storage, and insulation effects of sea-ice loss and their impact on 101 the lapse-rate feedback remains a challenge in comprehensive climate models. An additional mechanism for winter-amplified warming that has received less attention is the role of changes in the effective heat capacity of the surface layer in the Arctic. 
104 As in Dwyer et al. (2012), here we use the term "effective heat capacity" to refer to the

105 thermal inertia of the layer of material (e.g., sea ice, ocean) that sets the surface temperature

106 response to surface heat fluxes. Turbulent mixing in the ocean mixed layer couples a thick

107 layer of water to surface heat fluxes, giving the surface ocean a relatively large effective heat

108 capacity. As a result, ocean surface temperatures respond slowly to surface heat fluxes and

109 with a smaller amplitude than temperatures over land, where a much thinner surface layer

110 responds more quickly and strongly. Meanwhile, the effective heat capacity of sea ice

111 depends on whether it is melting or at temperatures below freezing. At the melting point, sea

112 ice has a large effective heat capacity because surface heat fluxes go toward latent heating to

113 melt ice rather than raising the surface temperature; melting sea ice thus acts like a very deep

114 ocean mixed layer. However, frozen sea ice has a small effective heat capacity because

115 surface heat fluxes go directly toward changing its surface temperature; frozen sea ice acts

116 like a shallow ocean mixed layer or a land-like surface. As frozen sea ice warms to the

117 melting point and then, ultimately, melts completely to expose open ocean, the effective heat

118 capacity of the surface increases. This slows the seasonal rate of warming and cooling and

119 thereby delays the phase and reduces the amplitude of the seasonal cycle of surface

120 temperature. As shown in Dwyer et al. (2012) for CMIP3 models, this phase delay and

121 amplitude reduction has also been found in earlier model generations (Manabe and Stouffer,

122 1980; Mann and Park, 1996) and is consistent with the warming pattern shown in Figure 1.

123 For a doubling of $\mathrm{CO}_{2}$, the large effective heat capacity of melting ice suppresses summer

124 warming, supporting a winter warming maximum. Under increased forcing, the amplitude

125 reduction from frozen sea ice to open ocean supports a large difference between very cold

126 winters over ice and warmer winters over ocean, contributing to peak winter warming. Peak

127 warming specifically in early winter is supported by the phase delay in ocean temperatures,

128 which are slower to warm to the seasonal maximum and to cool back below freezing. As a 
result, the transition from frozen sea ice to open ocean under increased forcing and the accompanying warming maximum occurs first in early winter before shifting to late winter. potential explanations for seasonality in Arctic warming that have been generated by diagnostic analysis of $\mathrm{CO}_{2}$ forcing experiments in comprehensive general circulation models

134 (GCMs). To disentangle these interconnected effects of sea-ice loss, here we employ an idealized single-column sea ice model (SCM) in addition to a GCM with certain sea-ice processes turned on and off. SCM experiments enable us to separate drivers of seasonality in Arctic warming, particularly the role of effective heat capacity changes alone, while GCM experiments offer insight into additional processes not included in the SCM, such as the lapse-rate feedback. Complementary to previous studies that have isolated the albedo effects

140 of sea ice using experiments with locked or unlocked albedo changes (Feldl et al., 2017;

141 Graversen et al., 2014), we isolate the role of non-albedo sea-ice thermodynamics by

142 comparing experiments with identical surface albedo changes, but with sea ice turned on or 143 off. Both the simple SCM and more complex GCM reveal a fundamental role of increasing 144 effective heat capacity in producing seasonality in Arctic warming, as the surface layer shifts 145 from sea ice below the freezing point to melting ice and open ocean. The results also highlight the role of sea ice effective heat capacity for inhibiting a positive summertime

147 lapse-rate feedback, which additionally supports a winter warming maximum.

\section{2. Seasonal Asymmetry in a Single-Column Sea Ice Model}

a. Model description

We employ an idealized SCM of the sea-ice-ocean-atmosphere system to investigate different mechanisms that have been proposed to cause seasonality in Arctic warming. We use the SCM developed and described by Eisenman and Wettlaufer (2009), which includes an 
idealized version of the Maykut and Untersteiner (1971) sea-ice thermodynamic equations and an idealized atmosphere. The SCM equations are repeated below. This model evolves the surface enthalpy $E$, which represents the latent energy of sea ice or, when no ice is present,

156 the sensible energy of the ocean mixed layer:

$$
E=\left\{\begin{aligned}
-L_{i} H_{i}, & E<0 \text { (sea ice) } \\
c_{m l} H_{m l} T_{m l}, & E>0 \text { (ocean) }
\end{aligned}\right.
$$

where $L_{i}$ is the latent heat of fusion for sea ice, $H_{i}$ is the sea-ice thickness, $c_{m l}$ is the specific heat capacity of the ocean mixed layer, $H_{m l}$ is depth of the ocean mixed layer $(50 \mathrm{~m})$, and $T_{m l}$ is the mixed-layer temperature departure from the freezing point, which is $0^{\circ} \mathrm{C}$ in this model.

$161 E$ evolves in response to the net surface energy flux, which includes solar forcing as a

162 function of the insolation $F_{s}(t)$ and surface albedo $\alpha(E)$, a linearized representation of 163 outgoing longwave radiation (OLR), basal heat flux $F_{B}$, sea ice export, and climate forcing

$164 \Delta F_{0}$, which can be varied from 0 to represent an increase in atmospheric $\mathrm{CO}_{2}$ :

$$
\frac{d E}{d t}=\underbrace{[1-\alpha(E)] F_{S}(t)}_{\text {solar }} \underbrace{-F_{0}(t)-F_{T}(t) T(t, E)}_{\text {OLR }}+\underbrace{F_{B}}_{\text {basal heat flux }}+\underbrace{v_{0} R(-E)}_{\text {ice export }}+\underbrace{\Delta F_{0}}_{\text {forcing }} .
$$
annually constant. $F_{0}(t)$ and $F_{T}(t)$ values have been derived as a function of atmospheric opacity, including the effects of climatological Arctic cloud cover (Maykut and Church, 1973), and atmospheric heat transport to the Arctic, which is based on observations of surface

170 air temperature to the south of the Arctic (Kalnay et al., 1996; Nakamura and Oort, 1988).

171 Central Arctic values from Maykut and Untersteiner (1971) are prescribed for $F_{S}(t)$ and $F_{B}$.

172 In the ice export term, $v_{o}=10 \%$ year $^{-1}$, and the linear ramp function $R(-E)$ is equal to $-E$ 173 when ice is present $(E \leq 0)$ and zero when there is no ice $(E>0)$. 
175 the surface energy flux and the upward heat flux through the ice: $-[1-\alpha(E)] F_{S}(t)+$

$176 F_{0}(t)+F_{T}(t) T^{*}(t, E)-\Delta F_{0}=\frac{-k_{i} T^{*}(t, E)}{H_{i}}=\frac{k_{i} L_{i} T^{*}(t, E)}{E}$, where $k_{i}$ is the thermal conductivity

177 of sea ice and $T^{*}$ is the surface temperature satisfying this balance. When this balance gives

178 surface temperatures below freezing $\left(T^{*}<0\right), T$ is set to $T^{*}$. When this balance gives surface

179 temperatures above freezing $\left(T^{*}>0\right)$ while ice is still present $(E<0), T$ is fixed at the

180 freezing point $\left(0^{\circ} \mathrm{C}\right)$ while the ice melts. Once the ocean is ice-free $(E>0), T$ equals the

181 enthalpy of the mixed layer divided by its effective heat capacity. The surface temperature for

182 these three regimes is given by

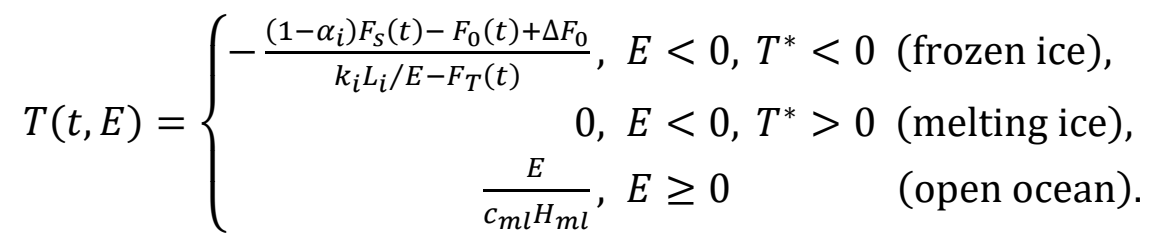

The albedo $\alpha(E)$ transitions smoothly from ice $\left(\alpha_{i}=0.68\right)$ to ocean $\left(\alpha_{m l}=0.2\right)$ with a characteristic smoothness set by $H_{\alpha}=0.5 \mathrm{~m}$ :

$$
\alpha(E)=\frac{\alpha_{m l}+\alpha_{i}}{2}+\frac{\alpha_{m l}-\alpha_{i}}{2} \tanh \left(\frac{E}{L_{i} H_{\alpha}}\right) .
$$

\section{b. Seasonal pattern of warming in the SCM}

To assess the extent to which this simple model can reproduce the pattern of seasonality in Arctic warming found in more complex models and observations, we compare steady-state solutions under varying degrees of forcing in the SCM with CESM2 preindustrial control and 1pctCO2-4xext experiments (Figure 2a,b). These CESM2 experiments are identical to those displayed in Figure 1, but Figure 2a shows surface temperature for $90^{\circ} \mathrm{N}$ rather than near-surface temperature for $70-90^{\circ} \mathrm{N}$ for better comparison with the SCM, which 
models surface temperature using observationally-based parameters for the central Arctic.

196 The bottom row in Figure 2 shows surface temperature anomalies for climate forcing experiments with respect to experiments with pre-industrial $\mathrm{CO}_{2}$ (for CESM2) or $\Delta F_{0}=0$ (for

198 the SCM).

The SCM experiment with $\Delta F_{0}=0$ produces a similar seasonal cycle to CESM2 under pre-industrial forcing. Greater climate forcing is required to produce a given warming in the SCM because it excludes many of the climate feedbacks in CESM2; rather than show equivalent forcings for both models, we include forcings that illustrate the full range of responses: annually ice-covered, seasonally ice-free, and annually ice-free conditions.

204 Despite neglecting many processes that additionally impact surface temperature, the SCM captures the key features of seasonality in Arctic warming found in CESM2. This includes (i) enhanced warming in winter compared to summer, (ii) asymmetry in winter warming, with peak warming initially occurring in early winter, and (iii) a shift to peak warming in late winter with greater forcing, once early winter temperatures exceed the freezing point. This warming pattern can also be described as a phase delay and amplitude reduction in the surface temperature as the surface layer shifts from perennial sea ice cover to seasonally and annually ice-free conditions.

\section{c. Causes of seasonal warming asymmetry in the SCM}

With the SCM capturing the seasonal pattern of Arctic warming found in observations

214 and more complex models, we next investigate factors contributing to this pattern in this

215 model. The SCM includes a representation of several mechanisms that have been suggested

216 to contribute to seasonality in Arctic warming: seasonally varying Planck and surface-albedo

217 feedbacks; changes in ice insulation and conductive heat flux as sea ice thins; and changes in

218 surface effective heat capacity as sea ice melts and exposes open ocean. Lapse-rate, cloud, 
and water-vapor feedbacks and changes in poleward heat transport are not included in the SCM, but are later explored in GCM experiments (Section 3) and by incorporating a lapserate feedback parameterization into the SCM (Section $2 \mathrm{f})$. asymmetry in the SCM. Enthalpy maximizes at the end of summer and increases most at this time under forcing, yielding a late summer maximum in the positive albedo feedback. The Planck feedback, equal to $-F_{T}(t)$ in the SCM, is a function of observations of climatological Arctic cloud fraction (Maykut and Church, 1973) which reach a maximum in September, producing a less-negative Planck feedback in fall and early winter than in late winter. While nonlinearity in the Stefan-Boltzmann equation would also promote seasonality in the Planck feedback and amplify cold-season warming in GCMs, the linearized Planck response in the SCM contributes to seasonality in warming only as a result of seasonality in climatological atmospheric opacity. The early winter warming maximum in the SCM is dampened when either an annual-mean Planck feedback $\left(\overline{F_{T}}\right)$ or constant ice albedo $\left(\alpha(E)=\alpha_{i}\right)$ is implemented (Figure S1), with the combined influence of these changes shown in Figure 2c.

234 Comparison of Figure $2 b$ and $2 c$ illustrates that the seasonally varying Planck feedback and particularly the albedo feedback reduce the amount of forcing necessary to support a transition to open ocean in early winter and an associated increase in early winter warming. However, seasonal asymmetry in warming persists even in the absence of seasonal asymmetry in feedbacks (Figure 2c), suggesting that the warming maximum in early winter

239 (and in late winter under increased forcing) is a fundamental property of warming with sea240 ice loss.

We next explore seasonality in warming contributed by changes in the conductive

242 heat flux through sea ice $\left(\frac{-k_{i} T}{H_{i}}\right)$, which maximizes in early winter as a result of both thinner 
243 ice and colder surface temperatures, and increases with increased forcing as ice thins. To

244 illustrate the effects of seasonality in conductive heat flux and its increase with forcing, we

245 compare the SCM with an annual-mean Planck feedback and constant ice albedo $\left(\overline{F_{T}}\right.$ and

$246 \alpha(E)=\alpha_{i}$; see Figure 2c) to the same SCM, but with a constant ice thickness $H_{i}$ used when

247 calculating the conductive heat flux through frozen ice (Figure 2d). This constant $H_{i}$ is set to

248 the annual-mean ice thickness from the $\Delta F_{0}=0$ experiment with $\overline{F_{T}}$ and $\alpha(E)=\alpha_{i}$. With

249 constant ice thickness in the conductive heat flux, warming for a given forcing is identical in

250 all months with frozen ice (Figure 2d). This illustrates that seasonally varying ice depth in the

251 conductive heat flux contributes to peak warming in early winter over frozen ice (Figure 2c).

252 Increasing conductive heat flux through thinner ice enhances surface warming in winter as

253 the surface forcing increases. In addition to enhanced warming over frozen ice, winter

254 warming as ice transitions to open ocean is also strengthened by starting from very cold

255 surface temperatures as a result of limited conductive heat flux through thick ice; this

256 warming is weakened when a thinner base-state ice depth is prescribed in the conductive heat

257 flux (Figure S2). The dependence of conductive heat flux on sea ice thickness thus

258 contributes to greater winter warming both over frozen ice and for the transition to open

259 ocean.

Importantly, even with seasonally constant warming over frozen ice in Figure 2d, the

261 transition from frozen ice to seasonally ice-free ocean with increased forcing produces an

262 early winter warming maximum, and the transition from seasonally to annually ice-free

263 conditions produces a late winter warming maximum. This intrinsic link between the ice-

264 ocean transition and peak Arctic warming, even in the absence of seasonal variations in

265 feedbacks or insulation effects, suggests that the seasonal pattern of warming fundamentally

266 stems from changes in the effective heat capacity of these surface types (Dwyer et al., 2012; 
267 Manabe \& Stouffer, 1980; Mann and Park, 1996). As frozen sea ice transitions to open ocean

268 in fall and early winter with increased forcing, the greater effective heat capacity of the ocean

269 mixed layer slows seasonal warming in summer and slows cooling back below freezing in

270 early winter, supporting a large increase in early winter temperatures relative to the much

271 colder temperatures of frozen ice under control forcing.

d. Contribution of effective heat capacity changes to the seasonal pattern of Arctic warming

We further investigate the role of effective heat capacity for seasonality in Arctic warming by explicitly modelling effective heat capacity changes in the SCM, and compare the results with an analytical solution based on Dwyer et al. (2012). Dwyer et al. illustrate heat capacity effects on seasonality using a simple energy balance model,

$$
C \frac{d T}{d t}=Q(t)-\beta T(t)
$$

where $C$ is effective heat capacity, $T(t)$ is surface temperature, $Q(t)$ is the seasonally varying surface forcing independent of temperature (including solar forcing), and $\beta$ is a constant, with $-\beta T(t)$ representing damping of the surface temperature response (including through OLR changes). This gives the following phase and amplitude relationships between the surface

282 forcing, $Q(t)=Q_{o} \cos \left(\omega t-\phi_{Q}\right)$, and the surface temperature, $T(t)=T_{o} \cos \left(\omega t-\phi_{T}\right)$,

283 with $\omega=2 \pi \mathrm{yr}^{-1}$ :

$$
\phi_{T}-\phi_{Q}=\arctan \frac{\omega C}{\beta},
$$

$$
T_{o}=\frac{Q_{o}}{\sqrt{\beta^{2}+\omega^{2} C^{2}}}
$$

286 In the limit of small effective heat capacity $(C \rightarrow 0)$, there is no phase lag between $Q(t)$ and

287 surface temperature, while a much larger effective heat capacity $(C \rightarrow \infty)$ gives a maximum phase delay of $90^{\circ}$, or three months for an annual harmonic forcing. A transition from frozen 
ice to open ocean with increased forcing would cause an increase in effective heat capacity and thus a phase delay (Eq. 6) and amplitude reduction (Eq. 7) in surface temperature, consistent with the SCM response in Figure 2d.

To explicitly model the effect of heat capacity differences between frozen ice, melting ice, and open ocean, we run the SCM as an ocean mixed layer, the effective heat capacity of which can be modified by changing the mixed layer depth $\left(C=c_{m l} H_{m l}\right)$. Without sea ice in this version of the model, Eq. 3 becomes $T(t, E)=\frac{E}{c_{m l} H_{m l}}$, ice export is set to zero, and there is no conductive heat flux. As above, we also apply an annual-mean Planck feedback and constant ice albedo $\left(\overline{F_{T}}\right.$ and $\left.\alpha(E)=\alpha_{i}\right)$ in order to isolate the impact of heat capacity changes alone on seasonality in Arctic warming. We perform four sets of experiments with this SCM: (i) using a mixed layer depth of $H_{m l}=1 \mathrm{~m}$ (representing the small effective heat capacity of frozen ice); (ii) using a mixed layer depth of $H_{m l}=50 \mathrm{~m}$ (representing the large effective heat capacity of open ocean); (iii) using a variable mixed layer depth that is $H_{m l}=1$ $\mathrm{m}$ when the surface temperature is below freezing, defined by $E<0$ (representing the small effective heat capacity of frozen ice) and becomes $H_{m l}=50 \mathrm{~m}$ when the surface temperature is at or above the melting point, defined by $E \geq 0$ (representing the large effective heat capacity of open ocean); and (iv), as in (iii) but using $H_{m l}=10^{6} \mathrm{~m}$ when $\mathrm{E} \geq 0$ (representing the very large effective heat capacity associated with the latent energy sink of sea ice melting at a nearly-constant temperature). representing open ocean shows a delayed phase and reduced amplitude in surface temperature

310 (Figure 3b) compared to experiment (i) with a shallow mixed layer representing frozen ice

311 (Figure 3a), while both experiments show a seasonally-uniform warming in response to 312 forcing. In experiment (iii), which allows a transition from the effective heat capacity of 
313 frozen ice for $E<0$ to that of ocean when $E \geq 0$ (Figure 3c), an increase in effective heat

314 capacity under forcing produces peak warming in early winter by delaying the phase and

315 reducing the amplitude of surface temperature (Figure 3c). Under greater forcing, this ice-

316 ocean transition and associated amplitude reduction from colder ice to warmer ocean

317 temperatures occurs later in the year, producing peak warming in late winter. Similarly,

318 experiment (iv), which allows a transition from the effective heat capacity of frozen ice for

$319 E<0$ to the much larger effective heat capacity of melting ice when $E \geq 0$ produces nearly

320 identical results to experiment (iii) with an early (shifting to late) winter warming maximum

321 under forcing, in addition to inhibiting summer warming over melting ice (Figure 3d).

We compare the SCM results to the Dwyer et al. (2012) analytic solution for the expected amplitude and phase shift of surface temperature by applying Eq. (6) and (7) to the 1-m and 50-m mixed-layer SCM, where

$$
Q(t)=\underbrace{\left[1-\alpha_{i}\right] F_{S}(t)}_{\text {solar }}-\underbrace{F_{0}(t)}_{\text {OLR }}+\underbrace{F_{B}}_{\text {basal heat flux }}+\underbrace{\Delta F_{0}}_{\text {forcing }}
$$

$$
\beta=F_{T}(t)
$$

327 Results are similar for the analytic solution (Figure S3a,b, grey lines) and SCM experiments

328 (Figure S3a,b, black lines), with small differences due to applying discrete monthly solar forcing and $F_{0}(t)$ to the SCM. When $F_{S}(t)$ is instead represented as a cosine function and the annual-mean value of $F_{0}(t)$ is used, the amplitude and phase shift of surface temperature in

331 the SCM exactly matches results from Eq. (6) and (7) (Figure S3c,d). These results from the

332 mixed-layer SCM and analytic solution demonstrate that the key features of Arctic seasonality in warming can be produced simply by representing how the effective heat capacity of the Arctic surface layer evolves with surface temperature. 
A final way to isolate the role of effective surface heat capacity changes and other thermodynamic processes is to compare SCM experiments with ice to SCM experiments with identical, prescribed albedo changes but no ice. Figure 4a-c shows the same SCM configurations as in Figure 2b-d for select forcing experiments illustrating annually icecovered, seasonally ice-free, and annually ice-free conditions (solid lines; Ice experiments).

341 Overlaid are results for the same SCM configurations, but with a 50-m mixed-layer SCM with no ice and with prescribed surface albedo from the Ice experiments (dashed lines; No ice, set albedo experiments). With identical albedo changes under increased forcing, these Ice and No ice, set albedo experiments differ only in their inclusion or exclusion of sea-ice thermodynamics.

In both the standard SCM (Figure 4a) and the SCM with an annual-mean Planck feedback and constant ice albedo (Figure 4b), ice thermodynamics suppress summer warming over melting ice and enhance winter warming. For surface temperatures below freezing, this enhanced winter warming results from increasing conductive heat flux through thinning ice. When ice thickness is kept constant for the conductive heat flux (Figure 4c), winter warming at temperatures below freezing is instead reduced in the Ice experiments compared to the No ice, set albedo experiments as a result of ice export changes in only the Ice experiments. Even with constant ice thickness in the conductive heat flux and reduced winter warming over frozen ice, the transition above freezing temperatures produces enhanced winter warming when ice thermodynamics are included due to a phase delay and amplitude reduction in temperature with increasing effective surface heat capacity. Instead, in the No ice, set albedo experiment, the constant effective surface heat capacity for the 50-m mixed layer gives seasonally-constant warming for all forcings. This illustrates the essential role of sea-ice thermodynamics, specifically conductive heat flux changes as frozen ice warms and effective 
heat capacity changes as frozen ice melts and transitions to open ocean, for the seasonal pattern of Arctic warming.

\section{f. Addition of a lapse-rate feedback to the SCM}

Based on analysis of comprehensive GCM experiments, Pithan and Mauritsen (2014) suggest that the winter-peaking lapse-rate feedback is an important driver of seasonality in Arctic warming. To estimate how much additional seasonality in warming the lapse-rate feedback would contribute to the SCM, we add a contribution from this feedback to the surface energy balance, multiplied by the surface warming under forcing compared to $\Delta F_{0}=$

0. We calculate the lapse-rate feedback for a doubling of $\mathrm{CO}_{2}$ compared to pre-industrial conditions in CESM slab ocean experiments, described in Section 3, for non-land gridpoints north of $70^{\circ} \mathrm{N}$. This gives a fairly constant lapse-rate feedback for gridpoints with belowfreezing surface temperatures under $\mathrm{CO}_{2}$ doubling, and a weaker lapse-rate feedback for gridpoints that exceed the freezing point under $\mathrm{CO}_{2}$ doubling. Since we add a lapse-rate

373 feedback to the SCM in a forcing experiment $\left(\Delta F_{0}=12\right)$ that does not warm above the freezing point, we apply the CESM lapse-rate feedback averaged only over gridpoints that remain below freezing under $\mathrm{CO}_{2}$ doubling $\left(1 \mathrm{~W} \mathrm{~m}^{-2} \mathrm{~K}^{-1}\right)$ to the SCM. We show this $\Delta F_{0}=$ 12 forcing experiment in the SCM because it produces warming of similar magnitude to the area-averaged non-land Arctic warming in the $\mathrm{CESM} \mathrm{CO} 2$ doubling experiments.

Surface temperatures with and without a lapse-rate feedback in the standard SCM are shown in Figure 5 for $\Delta F_{0}=12$ compared to $\Delta F_{0}=0$. In these experiments, the lapse-rate feedback increases winter warming by about 3 degrees, magnifying the early winter warming maximum that exists in the SCM without the lapse-rate feedback. Nevertheless, the majority of seasonality in warming in the SCM is still due to processes other than the lapse-rate feedback. For this forcing, these processes are primarily enhanced warming in winter due to 
an increase in conductive heat flux through thinning ice, and suppressed warming in summer due to the large effective heat capacity of melting ice.

\section{Seasonality of Arctic Warming With and Without Sea Ice in CESM}

The above results suggest that in the absence of seasonality in climate feedbacks, seasonality in Arctic warming is fundamentally driven by increasing conductive heat flux through thinning ice and increasing effective heat capacity as ice melts and exposes open ocean. Can we similarly isolate the role of sea ice thermodynamic effects within a GCM?

Complementary to previous GCM experiments isolating the impact of sea-ice albedo changes on Arctic warming (Feldl et al., 2017; Graversen et al., 2014), here we use idealized GCM experiments to isolate non-albedo thermodynamic effects of sea ice on Arctic warming.

While analogous to SCM experiments in Section 2e, these GCM experiments enable us to include not only the thermodynamic and climate feedback effects incorporated in the SCM, but also more complex polar climate feedbacks and changes in poleward heat transport that the SCM excludes.

a. CESM Experiments

We perform all experiments with the CESM (Hurrell et al., 2013) version 1.2.2, which uses the Community Atmosphere Model version 4 (CAM4; Neale et al., 2013) with a

401 horizontal resolution of $0.9^{\circ} \times 1.25^{\circ}$ and 26 vertical levels, the Community Land Model

402 version 4 (CLM4; Oleson et al., 2010) and the Los Alamos Sea Ice Model version 4 (CICE4;

403 Hunke and Lipscomb, 2008). For these experiments, CAM4 is coupled to a slab ocean model 404 (SOM) with a prescribed, spatially heterogeneous monthly climatology of ocean heat flux convergence taken from a fully-coupled pre-industrial control simulation (Bitz et al., 2012). 
407 to $0 \mathrm{~m}$ above sea level, this flattening has a negligible impact on Arctic surface temperatures

408 (Hahn et al., 2020), which are the focus here. including full sea-ice thermodynamics (called Ice) to experiments with no sea ice, in which ocean temperatures can cool below the freezing point (called No ice). As in the SCM, we also run experiments with no sea ice in which we prescribe climatological albedo values over nonland surfaces taken from the Ice experiments (called No ice, set albedo). In these No ice, set albedo experiments, the non-land albedo change under $\mathrm{CO}_{2}$ doubling is by design almost identical to the Ice experiments $\left(<0.7 \%\right.$ difference for $\left.70-90^{\circ} \mathrm{N}\right)$. Small differences may result from the way we prescribe albedo, using the climatological fraction of incoming visible solar radiation that is reflected at the surface in the Ice experiment to prescribe direct and diffuse, visible and near-infrared surface albedos in the No ice, set albedo experiment, with zero albedo change by default when there is no sunlight.

With nearly identical albedo changes under $\mathrm{CO}_{2}$ doubling in the Ice and No ice, set albedo experiments, differences between these experiments reflect non-albedo thermodynamic effects of sea ice. All remaining figures are shown for the Arctic from 70$90^{\circ} \mathrm{N}$ over non-land surfaces.

\section{b. Impact of sea-ice thermodynamics and albedo on Arctic warming} Ice (Figure 6a) compared to No ice, set albedo (Figure 6b) experiments. This is consistent with the small effective heat capacity of ice below freezing compared to open ocean, which gives a larger seasonal amplitude and earlier phasing in near-surface temperature in the Ice 
experiments. As in the fully-coupled CESM2 (Figure 1), the CESM SOM Ice experiments

432

433

434

435

436

438

439

440

441

442

443

444

445

446

447

448

450

451

simulate a summer minimum and early winter maximum in near-surface warming under $\mathrm{CO}_{2}$

doubling (Figure 6c). In contrast, warming is nearly constant year-round in experiments without sea ice. The main effect of ice albedo changes (No ice, set albedo compared to No ice) is to strengthen warming in the annual mean, with a slightly greater increase in fall warming than the rest of the year. The main impact of sea-ice thermodynamic effects (Ice compared to No ice, set albedo) is to reduce summer warming, as also seen in SCM experiments. Including thermodynamic effects also slightly increases early winter warming, although winter warming is more comparable for Ice compared to No ice, set albedo experiments in the GCM than in the SCM.

\section{c. Mechanisms linking sea ice to seasonality in Arctic warming}

Figure 6 illustrates that one way in which sea-ice thermodynamics contribute to seasonality in Arctic warming is through suppressing summer warming, consistent with the large effective heat capacity of melting ice. Enhanced early winter warming when including ice thermodynamics in the GCM is also consistent with the effects of increasing conductive heat flux as ice below freezing thins, as seen in the SCM, although additional climate feedbacks also contribute to GCM warming. A slight phase delay in surface temperature as ice melts under $\mathrm{CO}_{2}$ doubling (Figure 6a) would widen with a transition to a seasonally icefree Arctic under greater forcing (Figure 1), additionally supporting an early winter warming maximum as a result of effective heat capacity changes. Thus, the role of thermodynamics for seasonality in warming in the GCM appears to align with results in the SCM experiments.

In addition to these direct effects of sea-ice thermodynamics, we consider indirect effects of ice thermodynamics on the seasonal pattern of warming via impacts on the lapserate feedback. The small effective heat capacity of frozen ice gives surface temperatures a 
large seasonal amplitude that brings temperatures to the freezing point in summer, where they remain due to the very large effective heat capacity of melting ice. As a result of these relatively warm summer surface temperatures, the pre-industrial Ice experiment has weak summer stability (Figure 7a, solid light blue line), compared to strong surface temperature inversions during winter (Figure 7b). In contrast, the annually large effective heat capacity of the ocean surface layer in the pre-industrial No ice, set albedo experiment gives surface temperatures a small seasonal amplitude, so that they remain below the freezing point in summer (Figure 7a, dashed light blue line). This produces base-state summer inversions that, combined with the elimination of the latent energy sink of melting ice in this experiment, support stronger surface-trapped warming during summer under doubled $\mathrm{CO}_{2}$. These results suggest that in addition to suppressing summer warming due to the large effective heat capacity of melting ice, sea-ice thermodynamics may also promote seasonality in warming by inhibiting a positive summertime lapse-rate feedback.

To quantify contributions from the lapse-rate and other feedbacks to Arctic warming under $\mathrm{CO}_{2}$ doubling, we apply the radiative kernel method using CAM3 kernels (Shell et al., 2008; Soden et al., 2008). We also calculate the annual atmospheric heat transport (AHT) convergence as the difference between surface and net TOA fluxes, and additionally subtract atmospheric energy and moisture storage to calculate the seasonal cycle of AHT convergence, following Donohoe et al. (2020a). In addition to changes in $\mathrm{AHT}$ under $\mathrm{CO}_{2}$

474 doubling, we consider changes in the surface energy budget (SEB), which includes both ice 475 export changes and seasonal ocean heat storage in the CESM SOM. Energetic contributions 476 from each feedback $\left(\lambda_{i} \Delta T\right)$, the Planck response $\left(\lambda_{p} \Delta T\right), \mathrm{CO}_{2}$ forcing $(F)$, changes in SEB 477 and AHT, and a residual term $\left(\Delta R_{\text {res }}\right)$ are then converted into contributions to near-surface 


$$
F+\left(\lambda_{p}+\sum_{i} \lambda_{i}\right) \Delta T+\Delta A H T+\Delta S E B+\Delta R_{\text {res }}=0
$$

481 Annual, summer (June-July-August), and winter (December-January-February) warming 482 contributions are determined by dividing each term in Eq. (10), all in units of $\mathrm{W} \mathrm{m}^{-2}$, by the 483 magnitude of the non-land Arctic Planck response in the Ice experiment $\left(\lambda_{p, \text { Ice }}\right)$ in $\mathrm{Wm}^{-2} \mathrm{~K}^{-1}$ :

$$
\Delta T=-\frac{F}{\lambda_{p, I c e}}-\frac{\lambda_{p}^{\prime} \Delta T}{\lambda_{p, I c e}}-\frac{\sum_{i} \lambda_{i} \Delta T}{\lambda_{p, I c e}}-\frac{\Delta A H T}{\lambda_{p, I c e}}-\frac{\Delta S E B}{\lambda_{p, I c e}}-\frac{\Delta R_{r e s}}{\lambda_{p, I c e}},
$$

where $\lambda_{p}^{\prime}=\lambda_{p}-\lambda_{p, I c e}$ is the difference between the non-land Arctic Planck feedback for a 486 given experiment, $\lambda_{p}$, and $\lambda_{p, I c e}$.

In Figure 8, contributions to non-land Arctic warming in the Ice configuration of the CESM SOM are plotted along the horizontal axis, while contributions to warming in the No ice, set albedo configuration are plotted along the vertical axis. The albedo feedback is identical by design for both experiments. Greater annual-mean warming in the No ice, set albedo experiments compared to the Ice experiments is mainly contributed by a morepositive lapse-rate feedback (Figure 8a). This results from a stronger lapse-rate contribution to summer warming in the No ice, set albedo experiments (Figure 8b), while the lapse-rate contribution to winter warming is similar for both sets of experiments (Figure 8c). In addition to the lapse-rate feedback, negative $\triangle S E B$ due to reduced sea ice export under $\mathrm{CO}_{2}$ doubling slightly weakens annual warming in the Ice experiment compared to the No ice, set albedo experiment, consistent with the SCM experiments. Seasonally, the $\triangle S E B$ contribution indicates stronger energy transfer from the atmosphere to ocean in summer and from the 
ocean to atmosphere in winter in the Ice experiment, which also contributes to stronger seasonality in warming.

The Ice and No ice, set albedo experiments show similar DJF warming because

reduced winter ocean-to-atmosphere heat transfer in the No ice, set albedo experiment is compensated by increased winter poleward AHT. Despite reduced seasonal ocean heat storage, the winter lapse-rate feedback remains similarly strong in the No ice, set albedo experiment compared to the Ice experiment. In contrast to the hypothesis of Dai et al. (2019) and Chung et al. (2021), these results suggest that seasonal heat transfer related to sea-ice insulation loss is not necessary for a strong wintertime lapse-rate feedback.

A caveat to this feedback analysis in the No ice, set albedo experiments is that we use radiative kernels derived from experiments that include sea ice. In reality, we would expect that a colder and drier lower troposphere during summer in the No ice, set albedo experiments (Figure 7) would diminish the effect of atmospheric temperature changes on

512 TOA radiation (the temperature radiative kernel), and thus lead to a weaker summer lapse-

513 rate feedback than that shown in Figure 8. We test the sensitivity of feedback warming

514 contributions to this choice of radiative kernel by substituting kernels from other months and

515 find similar results, with the lapse-rate feedback still contributing most to greater summer warming in the No ice, set albedo experiment compared to the Ice experiment (see

517 Supplementary Text S1).

\section{4. Summary and Conclusions}

We use idealized experiments with certain sea ice processes individually inactivated in a GCM as well as a simpler model in order to disentangle potential causes of seasonality in

521 Arctic warming under $\mathrm{CO}_{2}$ forcing. A simple $\mathrm{SCM}$ is able to capture key features of Arctic warming seasonality: a summer minimum and early winter maximum in Arctic warming, 
523 shifting to a late winter maximum under greater forcing. Several factors contribute to the

524 warming seasonality in this model, including seasonality in the Planck response, albedo

525 feedback, and conductive heat flux through ice. In the absence of seasonality in climate

526 feedbacks, the SCM simulates peak early winter warming over ice below freezing due to

527 increasing conductive heat flux as ice thins, while the large effective heat capacity of melting

528 ice suppresses summer warming. When conductive heat flux variations with ice thickness are

529 further eliminated, the SCM still exhibits peak early winter warming due to a phase delay and

530 amplitude reduction in surface temperature as perennial sea ice transitions to a seasonally ice-

531 free ocean. While frozen sea ice warms quickly to the melting point in summer and cools

532 quickly to very cold winter temperatures in the zero-forcing experiment, exposed open ocean

533 in fall and early winter at increased forcing undergoes slower seasonal warming and cooling

534 due to its larger effective heat capacity, keeping temperatures above freezing later in the year

535 and supporting peak early winter warming relative to the zero-forcing experiment. With

536 greater forcing, this transition and associated amplitude reduction from colder ice to warmer

537 ocean temperatures occurs later in the year, producing peak warming in late winter. SCM

538 experiments demonstrate that representing the evolving effective heat capacity of the Arctic

539 surface layer is alone sufficient to reproduce the key features of seasonality in Arctic

540 warming.

Consistent with the SCM results, GCM experiments with doubled $\mathrm{CO}_{2}$ simulate peak

542 early winter warming and weak summer warming when sea ice is included. Comparison of

543 experiments with sea ice to those with identical, prescribed surface albedo changes but no sea

544 ice under $\mathrm{CO}_{2}$ forcing suggests that seasonality in Arctic warming depends on sea-ice

545 thermodynamic effects in both the SCM and GCM. Sea ice melt suppresses summer warming

546 while winter warming is amplified by increasing conductive heat flux through thinning ice 
547 and increasing effective heat capacity as ice melts and exposes open ocean. In the GCM, sea

548 ice also damps summer warming by inhibiting a positive summer lapse-rate feedback due to

549 weak base-state atmospheric stability (as a result of the small effective heat capacity of frozen

550 sea ice in non-summer months, which gives surface temperatures a large seasonal amplitude

551 and produces relatively warm summer surface temperatures) and minimal near-surface

552 warming in the presence of summer sea-ice melt. In winter, weaker seasonal ocean heat

553 release to the atmosphere in the No ice, set albedo GCM experiments is compensated by an

554 increase in poleward AHT. This supports similar winter warming for the No ice, set albedo

555 and the Ice experiments in the GCM, as does a strong winter lapse-rate feedback with only

556 the albedo effects of sea-ice loss.

Similar to previous studies, our results support a key role of sea ice in setting the seasonality of Arctic warming. Here we highlight effective heat capacity changes as a fundamental mechanism for this seasonality in warming, with results demonstrating the

560 utility of simpler models for understanding mechanisms of Arctic warming. Idealized GCM experiments also offer insight into the interconnected effects of sea ice on surface albedo changes, seasonal ocean heat storage, and insulation loss and their impacts on the lapse-rate feedback. These experiments suggest that a strong wintertime lapse-rate feedback can be

564 produced with the albedo effects of sea-ice loss alone, in contrast to the idea that seasonal

565 heat transfer related to sea-ice insulation loss is necessary to kickstart the winter lapse-rate 566 feedback.

568 frameworks like warming contribution analyses implicitly include interactions between

569 different contributors. Feedbacks like the lapse-rate feedback are also impacted by heat 570 capacity effects on surface warming, which are not explicitly quantified in this warming 
571 contribution framework. This limitation highlights a need for alternative frameworks, simpler

572 models, and idealized experiments to isolate the mechanisms of polar amplification and

573 interactions between mechanisms, as also suggested by Boeke et al. (2021) and Feldl et al.

574 (2020). The key role of effective heat capacity changes for seasonality in Arctic warming,

575 emphasized here with a simple model and idealized GCM experiments, also highlights a need

576 to accurately model the transition from perennial ice to seasonally ice-free conditions in

577 comprehensive GCMs in order to project the timing and magnitude of peak Arctic warming.

578 Acknowledgments

579 We acknowledge high-performance computing support from Cheyenne

580 (doi:10.5065/D6RX99HX) provided by NCAR's Computational and Information Systems

581 Laboratory (2019), sponsored by the National Science Foundation. LCH was supported by

582 the National Science Foundation (NSF) Graduate Research Fellowship Grant DGE-1762114

583 and the ARCS Foundation Fellowship. KCA was supported by National Science Foundation

584 Grants AGS-1752796 and OCE-1850900 and an Alfred P. Sloan Research Fellowship. IE

585 was supported by NSF OPP-1643445. CMB was supported by NSF OPP-1643431.

586 Data Availability Statement

587 The Eisenman and Wettlaufer (2009) single-column sea ice model is available from

588 https://eisenman-group.github.io (sea_ice_model_EW09.m). The CESM2 1pctCO2-4xext

589 experiments can be found in the Earth System Grid Federation (ESGF) repository at

590 https://esgf-node.llnl.gov/projects/esgf-1lnl/. Monthly climatologies of model output from

591 idealized CESM experiments are available at https://doi.org/10.5281/zenodo.4925048.

592

593 
595 Bintanja, R., Graversen, R. \& Hazeleger, W. (2011). Arctic winter warming amplified by the 596 thermal inversion and consequent low infrared cooling to space. Nature Geosci 4, 758761. https://doi.org/10.1038/ngeo1285

598 Bintanja, R., \& van der Linden, E. (2013). The changing seasonal climate in the Arctic. Scientific Reports 3, 1556. https://doi.org/10.1038/srep01556

Bitz, C.M., Shell, K.M., Gent, P.R., Bailey, D.A., Danabasoglu, G., Armour, K.C., Holland, M.M., \& Kiehl, J.T. (2012). Climate Sensitivity of the Community Climate System

602 Model, Version 4. Journal of Climate, 25, 3053-3070. https://doi.org/10.1175/JCLI-D-

603 $\underline{11-00290.1}$

604 Boeke, R. C., Taylor, P. C., \& Sejas, S. A. (2021). On the nature of the Arctic's positive 605 lapse-rate feedback. Geophys. Res. Lett. 48, 606 e2020GL091109. https://doi.org/10.1029/2020GL091109

607 Chung, E.-S., Ha, K.-J., Timmermann, A., Stuecker, M. F., Bodai, T., \& Lee, S.-

608 K. (2021). Cold-season Arctic amplification driven by Arctic ocean-mediated seasonal 609

610 energy transfer. Earth's Future 9,

611 Computational and Information Systems Laboratory. 2019. Cheyenne: HPE/SGI ICE XA

612 System (University Community Computing). Boulder, CO: National Center for

613 Atmospheric Research. https://doi.org/10.5065/D6RX99HX

614 Cronin, T. W., \& Jansen, M. F. (2015). Analytic radiative-advective equilibrium as a model 615 for high-latitude climate. Geophys. Res. Lett. 43, 449-457.

616 https://doi.org/10.1002/2015GL067172 
617 Dai, A., Luo, D., Song, M., \& Liu, J. (2019). Arctic amplification is caused by sea-ice loss

618 under increasing $\mathrm{CO}_{2}$. Nat. Commun. 10, 121. https://doi.org/10.1038/s41467-018-07954-

$619 \underline{9}$

620 Danabasoglu, G., Lamarque, J.-F., Bacmeister, J., Bailey, D. A., DuVivier, A. K., Edwards, 621 J., et al. (2020). The Community Earth System Model Version 2 (CESM2). Journal of 622 Advances in Modeling Earth Systems, 12, e2019MS001916. https://doi.org/10.1029/2019MS001916

624 Deser, C., Tomas, R., Alexander, M., \& Lawrence, D. (2010). The Seasonal Atmospheric 625 Response to Projected Arctic Sea Ice Loss in the Late Twenty-First Century. J. Clim. 23(2), 333-351. https://doi.org/10.1175/2009JCLI3053.1

627 Donohoe, A., Armour, K. C., Roe, G. H., Battisti, D. S., \& Hahn, L. (2020a). The partitioning 628 of meridional heat transport from the Last Glacial Maximum to $\mathrm{CO}_{2}$ quadrupling in 629

630 coupled climate models. J. Clim. 33(10), 4141-4165. https://doi.org/10.1175/JCLI-D-19-

631 Dwyer, J. G., Biasutti, M., Sobel, \& A. H. (2012). Projected changes in the seasonal cycle of 632 633 surface temperature. J. Clim. 25(18), 6359-6374. https://doi.org/10.1175/JCLI-D-11$\underline{00741.1}$

634 Eisenman, I., \& Wettlaufer, J. S. (2009). Nonlinear threshold behavior during the loss of 635 Arctic sea ice. PNAS 106 (1), 28-32. https://doi.org/10.1073/pnas.0806887106

636 Feldl, N., Bordoni, S., \& Merlis, T. M. (2017). Coupled high-latitude climate feedbacks and 637 their impact on atmospheric heat transport. J. Clim. 30, 189-201. https://doi.org/10.1175/JCLI-D-16-0324.1 
Feldl, N., Po-Chedley, S., Singh, H.K.A. et al. (2020). Sea ice and atmospheric circulation shape the high-latitude lapse rate feedback. npj Clim Atmos Sci 3, 41. https://doi.org/10.1038/s41612-020-00146-7

Goosse, H., Kay, J. E., Armour, K. C., Bodas-Salcedo, A., Chepfer, H., Docquier, D., et al. (2018). Quantifying climate feedbacks in polar regions. Nat. Commun. 9, 1919. https://doi.org/10.1038/s41467-018-04173-0

Graversen, R. G., Langen, P. L., \& Mauritsen, T. (2014). Polar amplification in CCSM4: Contributions from the lapse rate and surface albedo feedbacks. J.Clim. 27, 4433-4450. https://doi.org/10.1175/JCLI-D-13-00551.1

Hahn, L. C., Armour, K. C., Battisti, D. S., Donohoe, A., Pauling, A. G., \& Bitz, C. M. (2020). Antarctic elevation drives hemispheric asymmetry in polar lapse rate climatology and feedback. Geophys. Res. Lett. 47, e2020GL088965. https://doi.org/10.1029/2020GL088965

Hahn, L. C., Armour, K. C., Zelinka, M. D., Bitz, C. M., \& Donohoe, A. (2021). Contributions to Polar Amplification in CMIP5 and CMIP6 Models. Frontiers in Earth Science, in press.

Holland, M. M., \& Bitz, C. M. (2003). Polar amplification of climate change in coupled models. Clim. Dyn. 21, 221-232. https://doi.org/10.1007/s00382-003-0332-6

Hunke, E., \& Lipscomb, W. (2008). CICE: The Los Alamos sea ice model, documentation and software, version 4.0 (Tech. Rep. LA-CC-06-012). Los Alamos, NM: Los Alamos National Laboratory.

Hurrell, J. W., Holland, M. M., Gent, P. R., Ghan, S., Kay, J. E., Kushner, P. J., et al. (2013). The Community Earth System Model: A framework for collaborative 
664 Kalnay E, et al. (1996). The NCEP/NCAR 40-year reanalysis project. Bull. Am. Meteor. Soc.

665 77, 437-471. https://doi.org/10.1175/1520-

666

\section{7(1996)077\%3C0437:TNYRP\%3E2.0.CO;2}

667 Lu, J., \& Cai, M. (2009). Seasonality of polar surface warming amplification in climate

668 simulations. Geophys. Res. Lett. 36, L16704, https://doi.org/10.1029/2009GL040133

669

Manabe, S., \& Stouffer, R. J. (1980). Sensitivity of a global climate model to an increase of

670 $\mathrm{CO}_{2}$ concentration in the atmosphere. J. Geophys. Res. 85(C10), 5529-5554.

671 https://doi.org/10.1029/JC085iC10p05529

Mann, M. E., \& Park, J. (1996). Greenhouse warming and changes in the seasonal cycle of temperature: Model versus observations. Geophys. Res. Lett. 23, 1111-1114. https://doi.org/10.1029/96GL01066

Maykut, G. A., \& Untersteiner, N. (1971). Some results from a time-dependent thermodynamic model of sea ice. J. Geophys. Res. 76, 1550-1575.

\section{https://doi.org/10.1029/JC076i006p01550}

678

679

680

Maykut, G. A., \& Church, P. E. (1973). Radiation climate of Barrow, Alaska, 1962-66. J. Appl. Meteor. 12, 620-628. https://doi.org/10.1175/1520-

\section{0(1973)012\%3C0620:RCOBA\%3E2.0.CO;2}

681 Nakamura, N., \& Oort A. H. (1988). Atmospheric heat budgets of the polar-regions. $J$.

682 Geophys. Res. 93, 9510-9524. https://doi.org/10.1029/JD093iD08p09510

683 Neale, R. B., Richter, J., Park, S., Lauritzen, P. H., Vavrus, S. J., Rasch, P. J., \& Zhang, M. 684 (2013). The mean climate of the Community Atmosphere Model (CAM4) in forced SST 
685

686

687

688

689

690

691

692

693

694

695

696

697

698

699

700

701

702

703

704

705

706

707

and fully coupled experiments. Journal of Climate, 26, 5150-5168. https://doi.org/10.1175/JCLI-D-12-00236.1

Oleson, K., Lawrence, D., Bonan, G., Flanner, M., Kluzek, E., Lawrence, P., et al. (2010). Technical description of version 4.0 of the Community Land Model (CLM) (Tech. Rep. TN-478+STR). Boulder, CO: National Center for Atmospheric Research.

Payne, A. E., Jansen, M. F., \& Cronin, T. W. (2015). Conceptual model analysis of the influence of temperature feedbacks on polar amplification. Geophys. Res. Lett. 42, 95619570. https://doi.org/10.1002/2015GL065889

Pithan, F., \& Mauritsen, T. (2014). Arctic amplification dominated by temperature feedbacks in contemporary climate models. Nat. Geosci. 7, 181-184. https://doi.org/10.1038/ngeo2071

Pithan, F., Medeiros, B., \& Mauritsen, T. (2014). Mixed-phase clouds cause climate model biases in Arctic wintertime temperature inversions. Clim. Dyn. 43, 289-303. https://doi.org/10.1007/s00382-013-1964-9

Screen, J. A., \& Simmonds, I. (2010a). The central role of diminishing sea ice in recent Arctic temperature amplification. Nature 464, 1334-1337. https://doi.org/10.1038/nature09051

Screen, J. A., \& Simmonds, I. (2010b). Increasing fall-winter energy loss from the Arctic Ocean and its role in Arctic temperature amplification. Geophys. Res. Lett. 37, L16707. https://doi.org/10.1029/2010GL044136

Sejas, S. A., Cai, M., Hu, A., Meehl, G. A., Washington, W., \& Taylor, P. C. (2014). Individual Feedback Contributions to the Seasonality of Surface Warming. $J$. Clim. 27(14), 5653-5669. https://doi.org/10.1175/JCLI-D-13-00658.1 
Serreze, M. C., Barrett, A. P., Stroeve, J. C., Kindig, D. N., \& Holland, M. M. (2009). The emergence of surface-based Arctic amplification. The Cryosphere 3, 11-19. https://doi.org/10.5194/tc-3-11-2009

Shell, K. M., Kiehl, J. T., \& Shields, C. A. (2008). Using the radiative kernel technique to calculate climate feedbacks in NCAR's Community Atmospheric Model. Journal of Climate, 21, 2269-2282. https://doi.org/10.1175/2007JCLI2044.1

Soden, B. J., Held, I. M., Colman, R., Shell, K. M., Kiehl, J. T., \& Shield, C. A. (2008). Quantifying climate feedbacks using radiative kernels. Journal of Climate, 21, 3504-3520. https://doi.org/10.1175/2007JCLI2110.1

Taylor, K. E., Crucifix, M., Braconnot, P., Hewitt, C. D., Doutriaux, C., Broccoli, A. J., \& Webb, M. J. (2007). Estimating shortwave radiative forcing and response in climate models. J. Clim. 20(11), 2530-2543. https://doi.org/10.1175/JCLI4143.1

Wagner, T. J. W., \& Eisenman, I. (2015). False alarms: How early warning signals falsely predict abrupt sea ice loss. Geophys. Res. Lett. 42, 10,333-10,341. https://doi.org/10.1002/2015GL066297

Yoshimori, M., Abe-Ouchi, A., Watanabe, M., Oka, A., \& Ogura, T. (2014). Robust Seasonality of Arctic Warming Processes in Two Different Versions of the MIROC GCM. J. Clim. 27(16), 6358-6375. https://doi.org/10.1175/JCLI-D-14-00086.1 

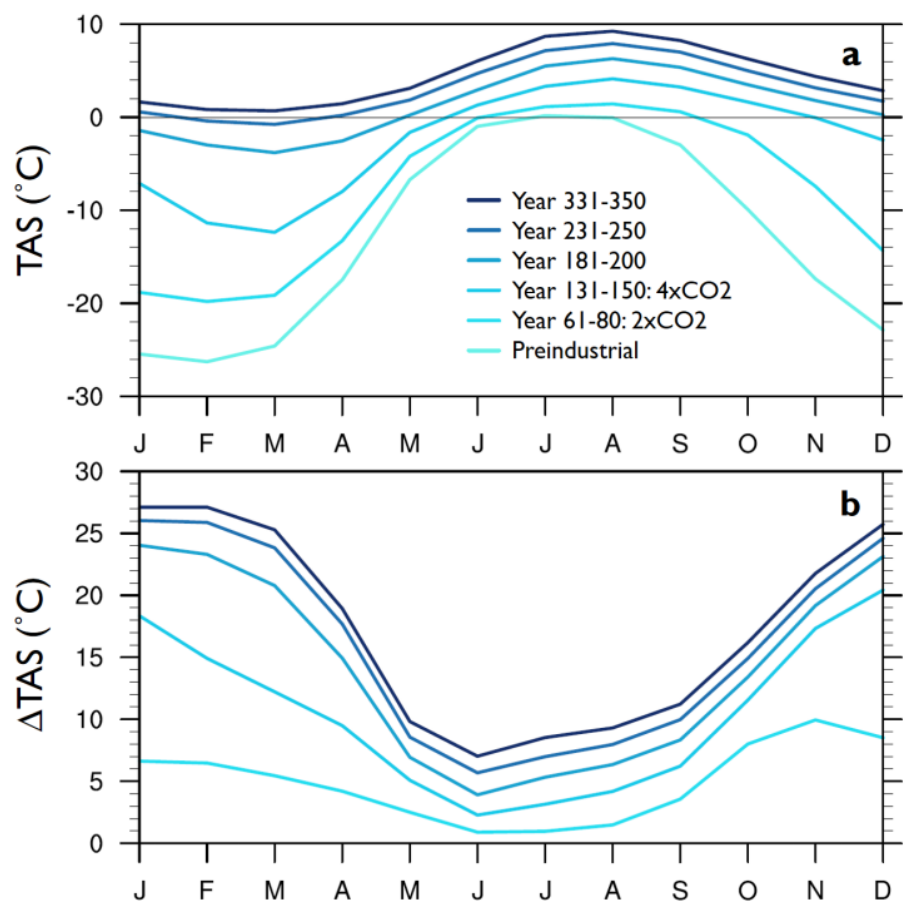

732 Figure 1. (a) Near-surface air temperature (TAS; ${ }^{\circ} \mathrm{C}$ ) over non-land surfaces from $70-90^{\circ} \mathrm{N}$ in

733 a 350-year-long $1 \% \mathrm{yr}^{-1} \mathrm{CO}_{2}$ ramping experiment (1pctCO2-4xext) in CESM2 and a 150-

734 year-long pre-industrial control (piControl) experiment from which it was initialized; averages are taken over years 1-150 of the piControl experiment and over selected 20-year periods of the 1pctCO2-4xext experiment, with years 61-80 centered on the time of $\mathrm{CO}_{2}$ doubling and years 131-150 centered on the time of $\mathrm{CO}_{2}$ quadrupling. (b) TAS anomalies for each period in the $1 p c t C O 2-4 x e x t$ experiment calculated relative to the piControl experiment. 


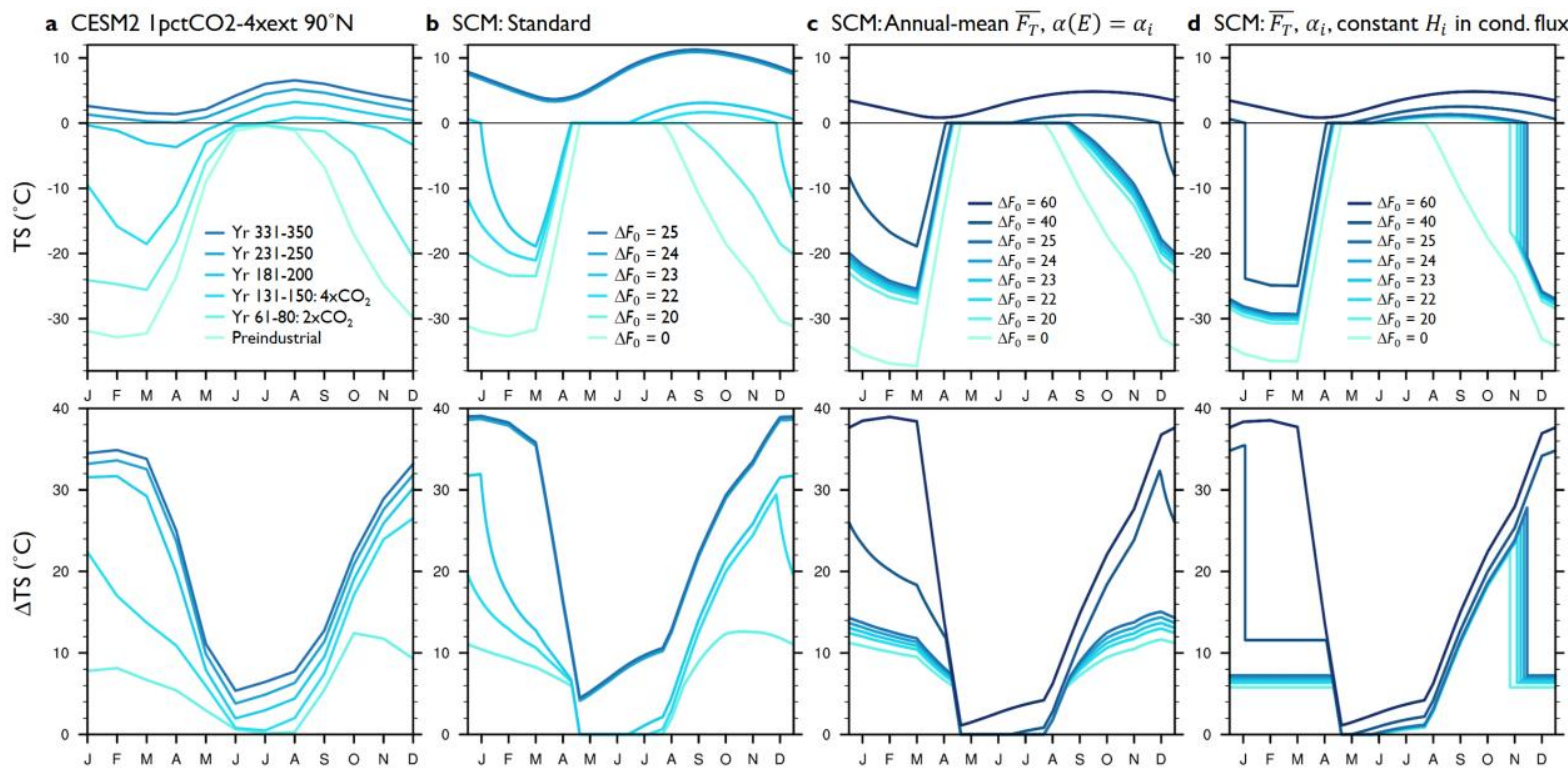

743 Figure 2. (a) Surface temperature (TS; ${ }^{\circ} \mathrm{C}$ ) for the 1pctCO2-4xext and piControl experiments

744 at $90^{\circ} \mathrm{N}$ in CESM2, and for surface forcing experiments in (b) the standard SCM, (c) the

745 SCM with annual-mean $F_{T}(t)$ and constant $\alpha(E)=\alpha_{i}$, and (d) the SCM with annual-mean

$746 F_{T}(t)$, constant $\alpha(E)=\alpha_{i}$, and constant ice thickness $H_{i}$ when calculating the conductive

747 heat flux through frozen ice, which is set to the annual-mean $H_{i}$ from the $\Delta F_{0}=0$ experiment

748 with annual-mean $F_{T}(t)$ and constant $\alpha(E)=\alpha_{i}$. The bottom row shows TS anomalies

749 compared to pre-industrial $\mathrm{CO}_{2}$ (for CESM2) or $\Delta F_{0}=0$ (for the $\mathrm{SCM}$ ). 
a $\mathrm{H}_{\mathrm{ml}}=\mathrm{I} \mathrm{m}$
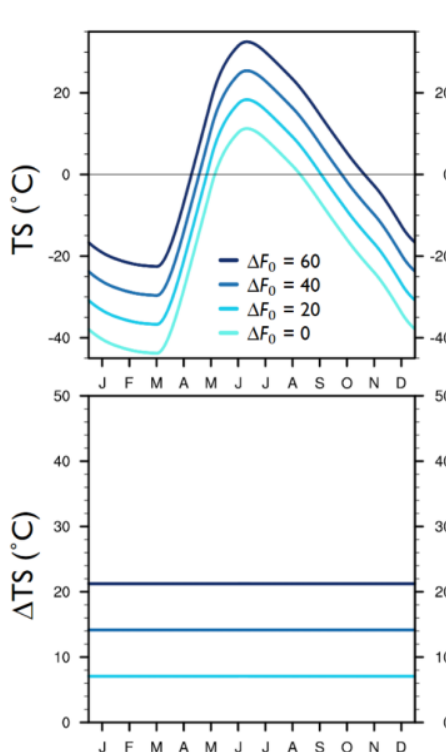

b $\mathrm{H}_{\mathrm{ml}}=50 \mathrm{~m}$

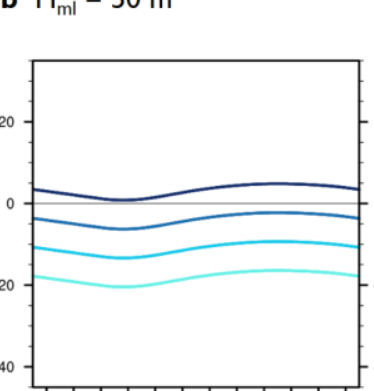

c $\mathrm{H}_{\mathrm{ml}}(\mathrm{E}<0)=\mathrm{I} \mathrm{m}$

$H_{m(}(E \geq 0)=50 m$

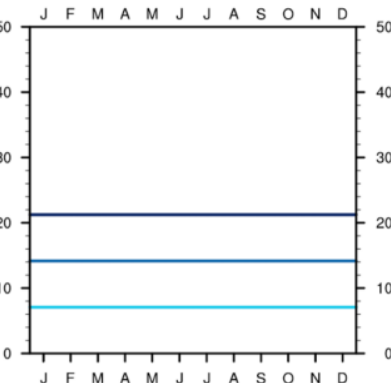

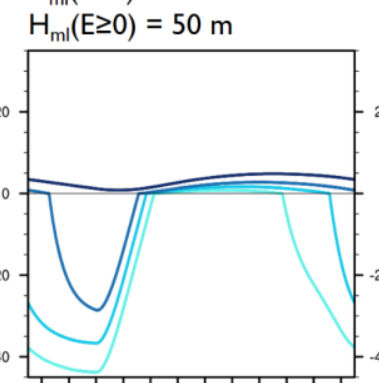

d $\mathrm{H}_{\mathrm{ml}}(\mathrm{E}<0)=1 \mathrm{~m}$

$H_{m 1}(E \geq 0)=10^{6} \mathrm{~m}$
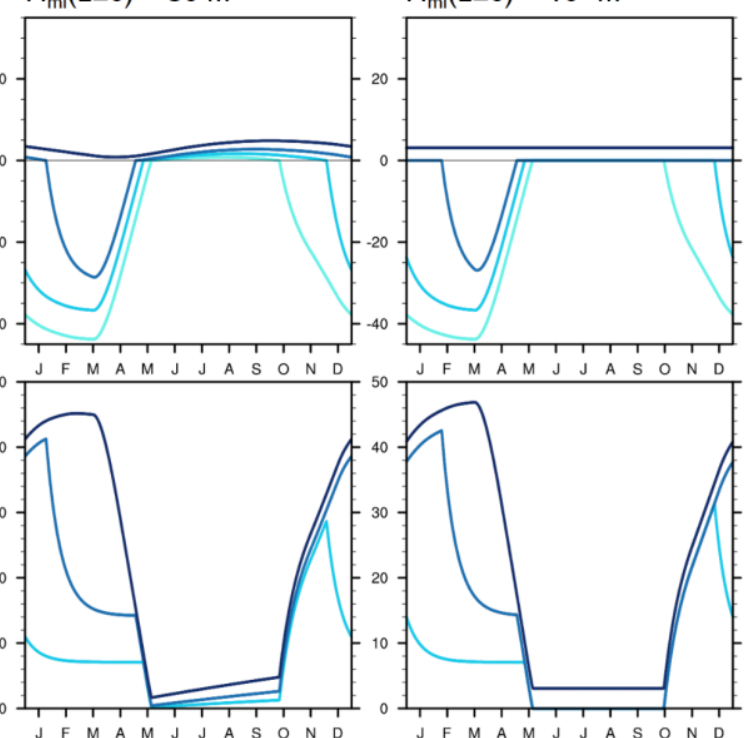

752 Figure 3. Surface temperature $\left(\mathrm{TS} ;{ }^{\circ} \mathrm{C}\right)$ for various surface forcings and mixed-layer depths in

753 the SCM run as a mixed layer with annual-mean $F_{T}(t)$ and constant $\alpha(E)=\alpha_{i}$. TS

754 anomalies for each forcing experiment compared to $\Delta F_{0}=0$ are shown in the bottom row. 


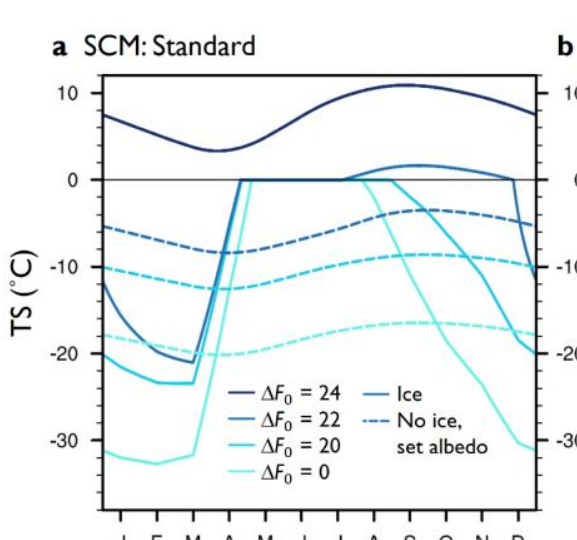

b SCM:Annual-mean $\overline{F_{T}}, \alpha(E)=\alpha_{i}$

c SCM: $\overline{F_{T}}, \alpha_{i}$, constant $H_{i}$ in cond. flux
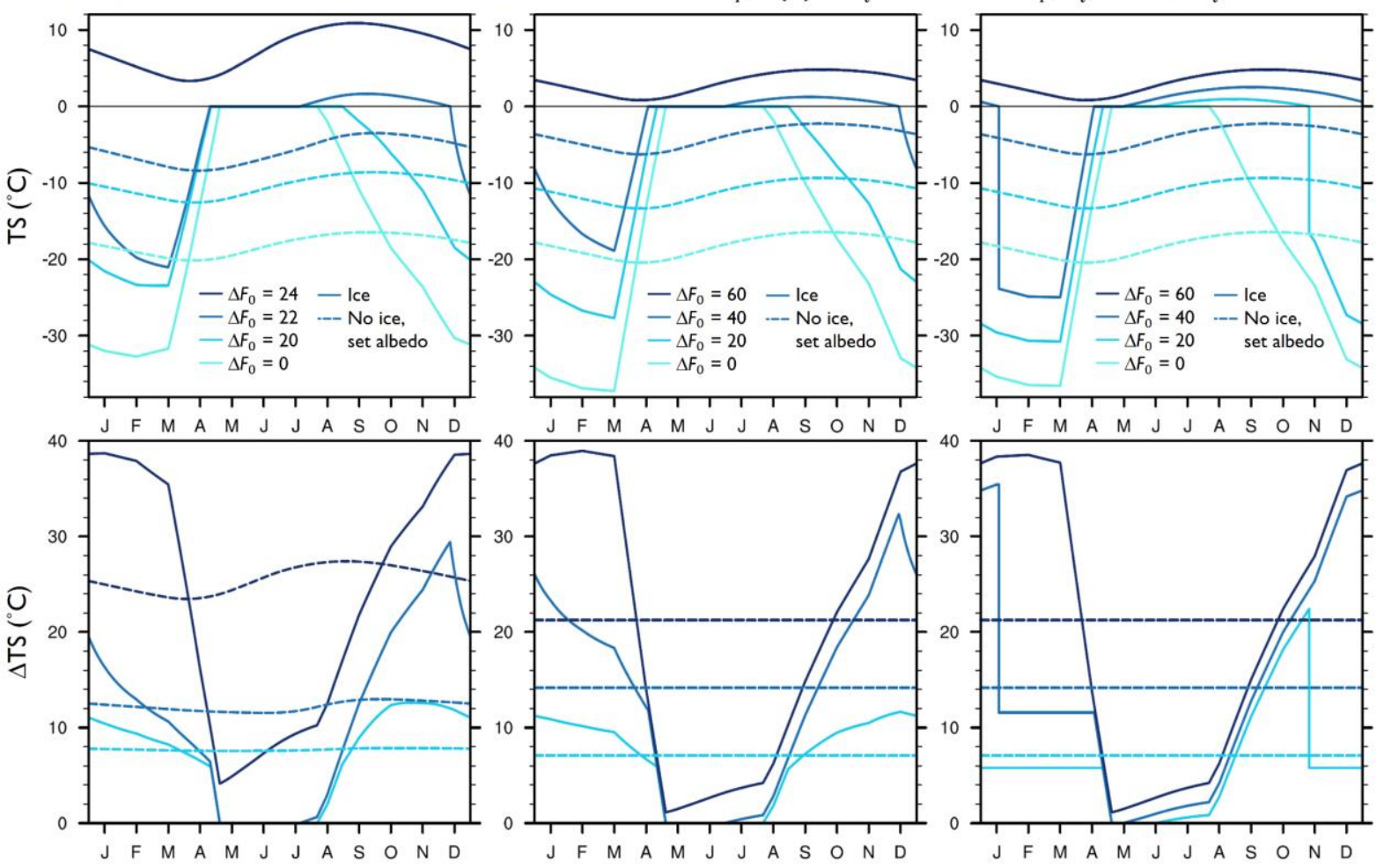

766 Figure 4. As in Figure 2b-d for select surface forcing experiments, solid lines show surface

767 temperature $\left(\mathrm{TS} ;{ }^{\circ} \mathrm{C}\right.$ ) in (a) the standard SCM, (b) the SCM with annual-mean $F_{T}(t)$ and

768 constant $\alpha(E)=\alpha_{i}$, and (c) the SCM with annual-mean $F_{T}(t)$, constant $\alpha(E)=\alpha_{i}$, and

769 constant ice thickness $H_{i}$ when calculating the conductive heat flux through frozen ice, which

770 is set to the annual-mean $H_{i}$ from the $\Delta F_{0}=0$ experiment with annual-mean $F_{T}(t)$ and

771 constant $\alpha(E)=\alpha_{i}$. Dashed lines show TS for identical experiments, but with a mixed-layer

772 SCM and prescribed surface albedo from the experiments with ice. The bottom row shows

TS anomalies compared to the $\Delta F_{0}=0$ experiment. 

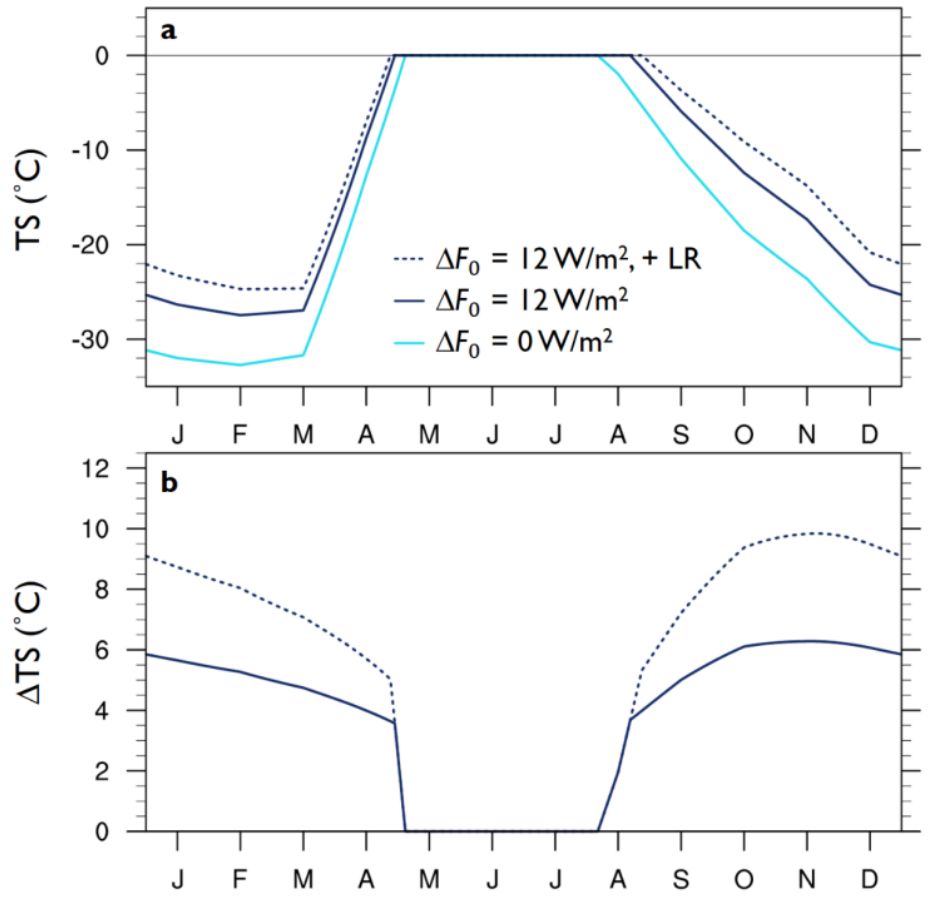

777 Figure 5. (a) Surface temperature $\left(\mathrm{TS} ;{ }^{\circ} \mathrm{C}\right)$ and (b) anomalies in TS for $\Delta F_{0}=12$ compared to

$778 \Delta F_{0}=0$ in the standard SCM (solid lines) and the standard SCM with a simple lapse-rate

779 feedback added (dashed line).

780

781

782

783

784

785

786

787

788 

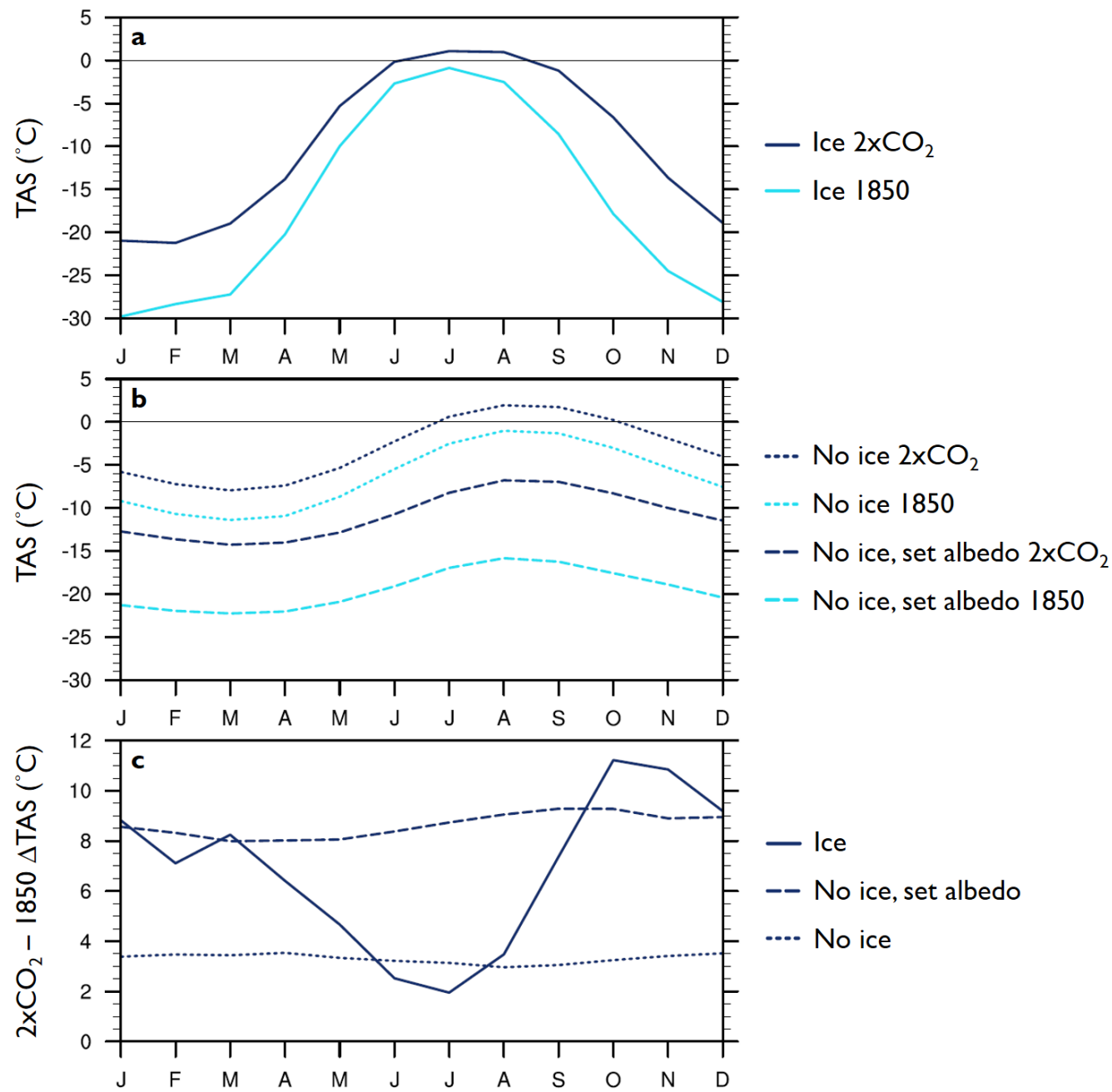

790 Figure 6. Near-surface temperature $\left(\mathrm{TAS} ;{ }^{\circ} \mathrm{C}\right)$ over non-land surfaces from $70-90^{\circ} \mathrm{N}$ for the

791 CESM SOM (a) Ice experiment and (b) No ice and No ice, set albedo experiments under pre-

792 industrial (light blue) and doubled $\mathrm{CO}_{2}$ (dark blue). (c) TAS anomalies for doubled $\mathrm{CO}_{2}$

793 compared to pre-industrial experiments (e.g. Ice $=$ Ice $2 \mathrm{xCO}_{2}$ minus Ice $1850 ;$ No ice $=$ No

794 ice $2 \mathrm{xCO}_{2}$ minus No ice 1850$)$.

795

796

797

798 



800 Figure 7. $(\mathrm{a}, \mathrm{b})$ Atmospheric temperature $\left({ }^{\circ} \mathrm{C}\right)$ and $(\mathrm{c}, \mathrm{d})$ specific humidity $(\mathrm{g} / \mathrm{kg})$ over non-

801 land surfaces from $70-90^{\circ} \mathrm{N}$ for June-July-August (JJA; a,c) and December-January-February

802 (DJF; b,d) in the Ice (solid) and No ice, set albedo (dashed) CESM SOM experiments under

803 pre-industrial conditions (light blue) and doubled $\mathrm{CO}_{2}$ (dark blue).

804

805

806

807

808

809

810 




811

812 Figure 8. Contributions to (a) annual-mean, (b) JJA, and (c) DJF warming $\left({ }^{\circ} \mathrm{C}\right)$ over non-land

813 surfaces from $70-90^{\circ} \mathrm{N}$ under $\mathrm{CO}_{2}$ doubling in the CESM SOM in the Ice configuration

814 (horizontal axis) and No ice, set albedo configuration (vertical axis). Warming contributions

815 are shown for the lapse-rate (LR), surface albedo (A), water-vapor (WV), and cloud (C)

816 feedbacks, the variation in the Planck response from its value in the Ice experiment (P'), $\mathrm{CO}_{2}$

817 forcing $\left(\mathrm{CO}_{2}\right)$, change atmospheric heat transport convergence $(\triangle \mathrm{AHT})$ and surface energy

818 budget $(\triangle \mathrm{SEB})$, which includes ice export and seasonal ocean heat storage, and residual term

819 (Res).

820

821

822

823

824

825

826

827 
829 Text S1. Kernel sensitivity test for the No ice, set albedo experiments

830

831

832

833

834

835

836

837

838

839

840

841

842

843

844

845

846

847

848

849

850

851

852

853

854

855

856

857
To test the sensitivity of feedback warming contributions in summer to the choice of radiative kernels for the No ice, set albedo experiments, we apply radiative kernels for the month of October to the months of June, July, and August to calculate longwave feedbacks. October near-surface temperature and specific humidity in the Ice experiment are more comparable with summer pre-industrial conditions in the No ice, set albedo experiment, although October in the Ice experiment is much colder and drier aloft (Figure S4). Summer feedback calculations with the October kernels should therefore give underestimated longwave feedbacks, but provide a useful kernel sensitivity test in comparison with the potentially overestimated longwave feedbacks shown in Figure 8. For the shortwave feedbacks, we apply the approximate partial radiative perturbation method of Taylor et al. (2007) as an alternative to the kernel method. The results of these alternative feedback calculations are shown in Figure S5. Although the summer lapse-rate feedback contribution for the No ice, set albedo experiment is slightly reduced, warming contributions are largely similar to those shown in Figure 8, and the lapse-rate feedback still contributes most to greater summer warming in the No ice, set albedo experiment compared to the Ice experiment. 


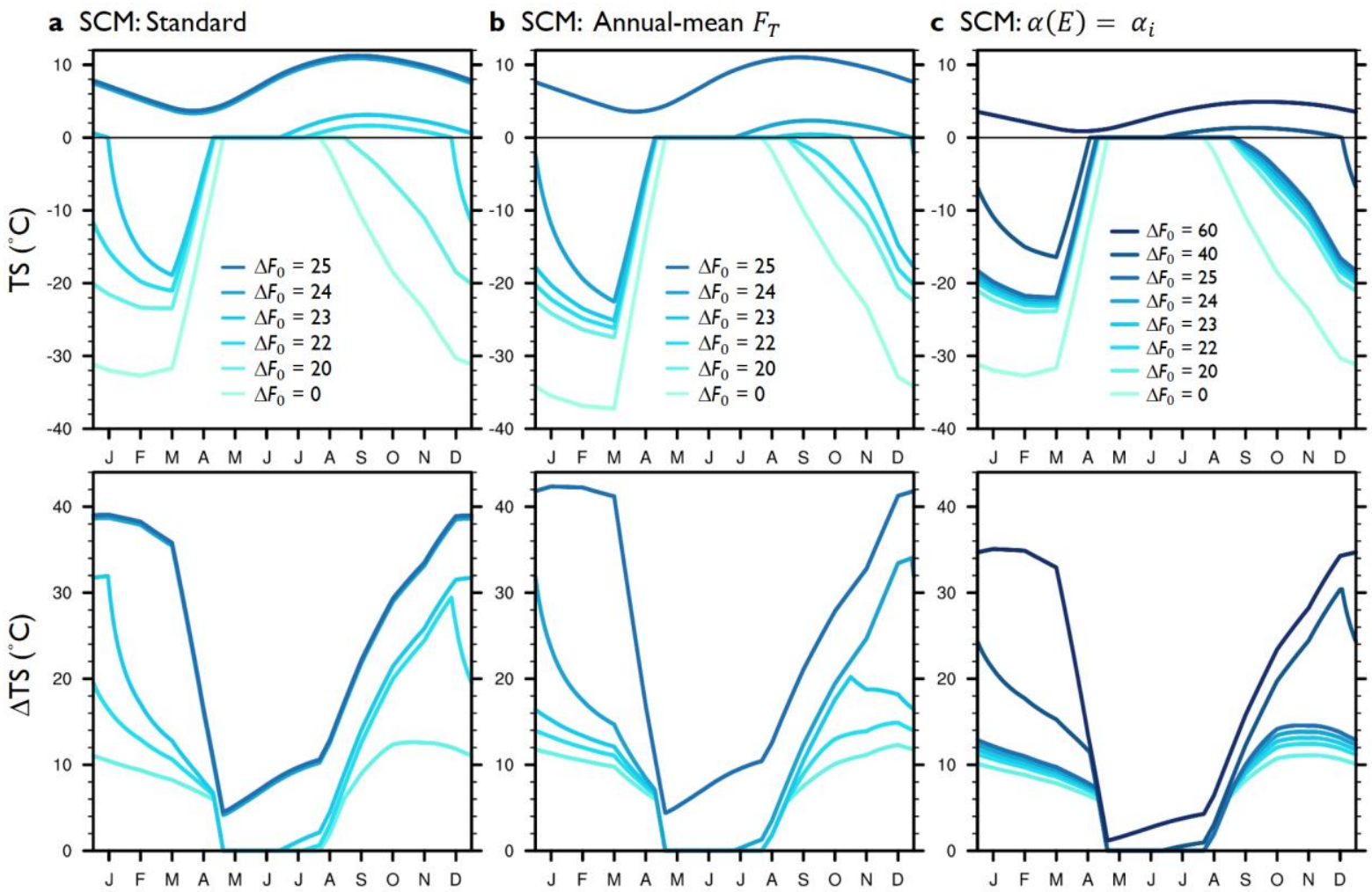

859 Figure S1. Surface temperature $\left(\mathrm{TS} ;{ }^{\circ} \mathrm{C}\right)$ for surface forcing experiments in (a) the standard

$860 \mathrm{SCM}$, (c) the SCM with annual-mean $F_{T}(t)$, and (c) the SCM with constant $\alpha(E)=\alpha_{i}$. The

861 bottom row shows TS anomalies compared to the $\Delta F_{0}=0$ experiment. 




865 Figure S2. As in Figure $2 \mathrm{~d}$, surface temperature $\left(\mathrm{TS} ;{ }^{\circ} \mathrm{C}\right)$ for surface forcing experiments in

866 the SCM with annual-mean $F_{T}(t)$, constant $\alpha(E)=\alpha_{i}$, and constant ice thickness $H_{i}$ when

867 calculating the conductive heat flux through frozen ice, which is set to the annual-mean $H_{i}$

868 from (a) the $\Delta F_{0}=0$ experiment $\left(H_{i}=3.2 \mathrm{~m}\right)$ and (b) the $\Delta F_{0}=25$ experiment $\left(H_{i}=1.0 \mathrm{~m}\right)$

869 with annual-mean $F_{T}(t)$ and constant $\alpha(E)=\alpha_{i}$. The bottom row shows TS anomalies

870 compared to the $\Delta F_{0}=0$ experiment. 

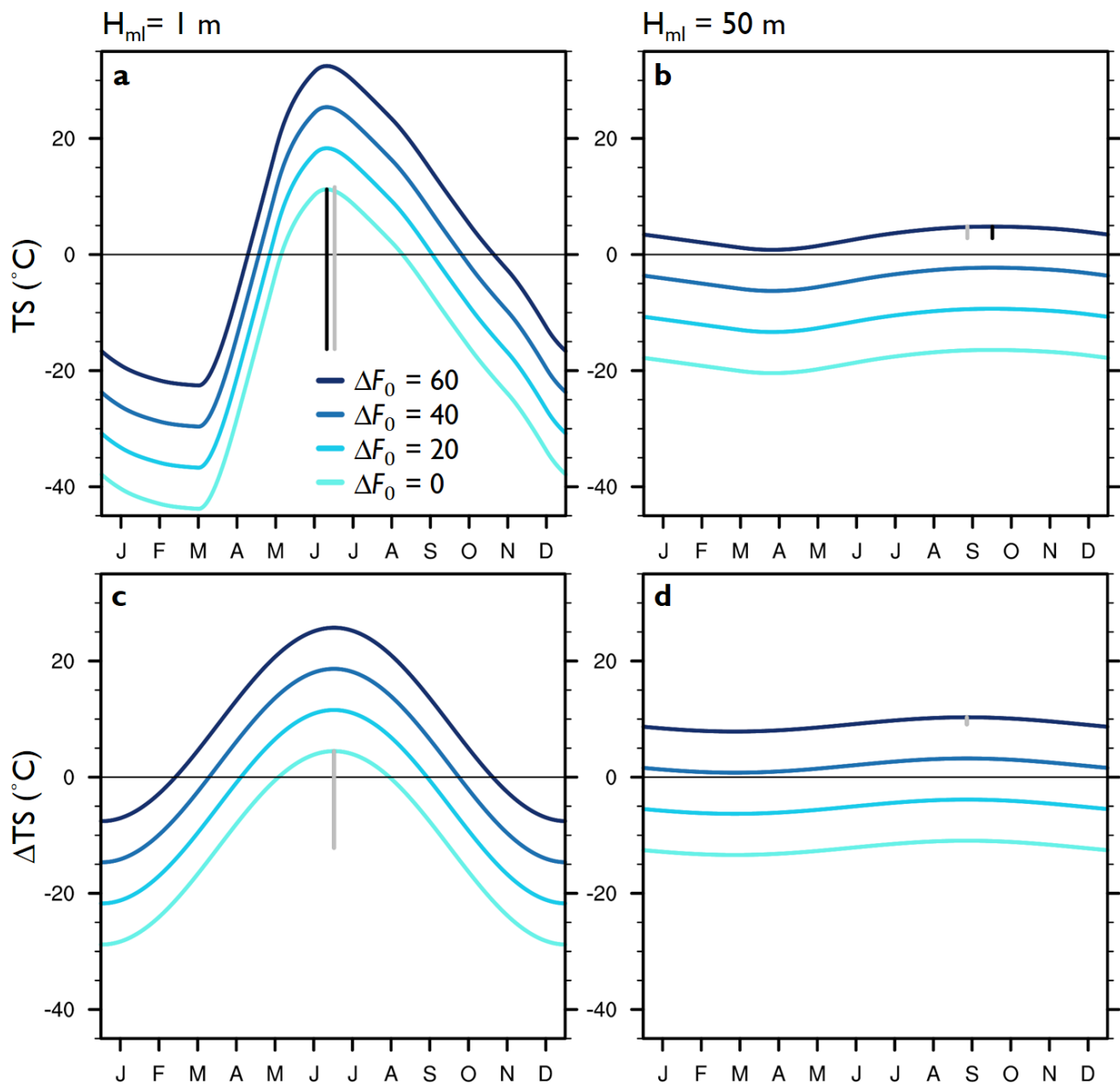

872 Figure S3. As in Figure 3a,b top, for $(\mathrm{a}, \mathrm{b})$ the mixed-layer SCM with annual-mean $F_{T}(t)$ and

873 constant $\alpha(E)=\alpha_{i}$, and (c,d) the same model, but with sinusoidal solar forcing $F_{S}(t)$ and

874 annual-mean $F_{0}(t)$. The black vertical lines indicate the timing and amplitude of maximum

875 surface temperature for the SCM, while the grey lines show the analytical solution.

876

877

878

879

880 

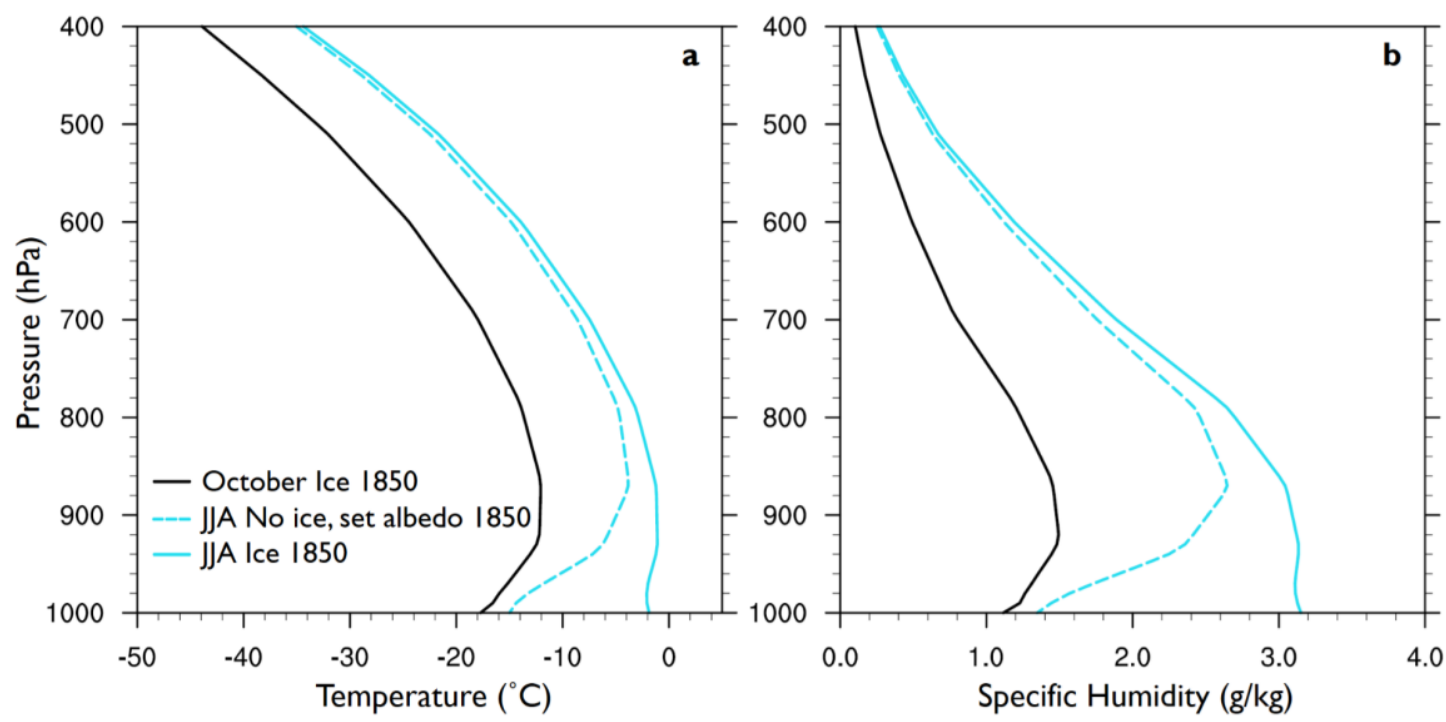

881

882 Figure S4. (a) Atmospheric temperature $\left({ }^{\circ} \mathrm{C}\right)$ and (b) specific humidity $(\mathrm{g} / \mathrm{kg})$ over non-land

883 surfaces from $70-90^{\circ} \mathrm{N}$ under pre-industrial forcing in the $N o$ ice, set albedo experiment

884 during June-July-August (JJA; dashed light blue) and in the Ice experiment during JJA (solid 885 light blue) and October (black).

886

887

888

889

890

891

892

893 

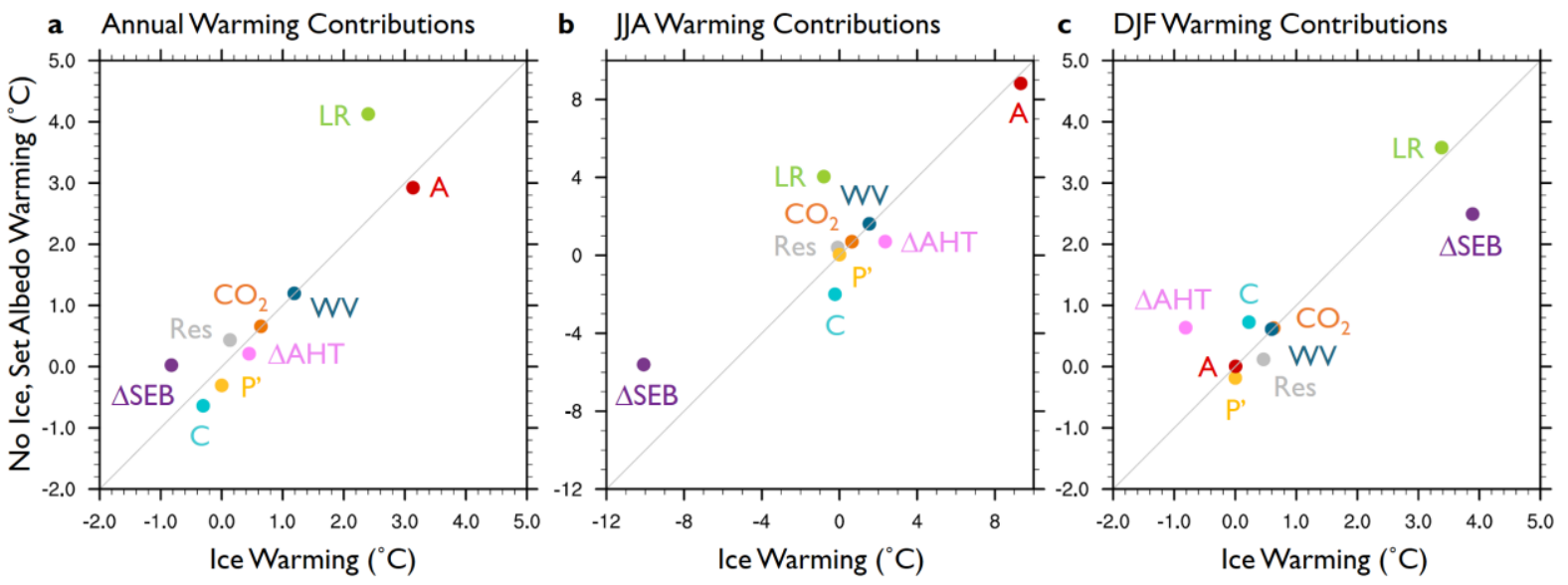

894

Figure S5. As in Figure 8, but using October radiative kernels to calculate JJA longwave

896 feedbacks and using the APRP method to calculate all shortwave feedbacks: contributions to

897 (a) annual-mean, (b) JJA, and (c) DJF warming $\left({ }^{\circ} \mathrm{C}\right.$ ) over non-land surfaces from $70-90^{\circ} \mathrm{N}$

898 under $\mathrm{CO}_{2}$ doubling in CESM Ice and No ice, set albedo experiments. Warming contributions

899 are shown for the lapse-rate (LR), surface albedo (A), water-vapor (WV), and cloud (C)

900 feedbacks, the variation in the Planck response from its value in the Ice experiment ( $\left.\mathrm{P}^{\prime}\right), \mathrm{CO}_{2}$

901 forcing $\left(\mathrm{CO}_{2}\right)$, change atmospheric heat transport convergence $(\triangle \mathrm{AHT})$ and surface energy

902 budget $(\triangle \mathrm{SEB})$, which includes ice export and seasonal ocean heat storage, and residual term 903 (Res). 